\title{
Investigation of tuned mass damper efficiency in controlling nonlinear behavior of structure models subjected to near fault earthquakes
}

\author{
Author: Reza RoshanMehr \\ Master of Civil Engineering - Earthquake Engineering -Islamic Azad University, Shabestar Branch
}

\section{Introduction}

One of the most important problems faced by most of the large cities in the world is the damages caused by natural disasters such as earthquakes, floods, fire, etc. Iran is considered as one of the vulnerable countries in terms of the occurrence of natural disasters, special earthquake, and many financial losses and casualties are annually made by natural disasters. One of the most important issues in the field of structural engineering is to reduce the damage caused by these natural disasters.An earthquake is one of the events that precise prediction ofthe time and place of its occurrence is still impossible despite the many research done on it.That is why one of the most important challenges for structural and earthquake engineers is to find a tool for dealing with the damages caused by earthquake.

One perspective oncoping with the seismic vibrations is to provide sufficient rigidity and strength in the structure to withstand lateral loads in the domain of permissible deformations. In this method, the main factor in energy absorption and dissipation is structural damping, part of which is due to the intrinsic damping of constituent materials and components of structure, and another part of it is due to the inelastic behavior of materials. Due to the limitations in structural deformation, it is impossible to allow the structure to enter inelastic zone more than a certain amount, and therefore using high strength and rigidity to cope with earthquake loads is inevitable, which can ultimately lead to an uneconomical design. Another perspective is to use the methods for the dissipation of reduction of energy transferred to the structure by external stimulations in order to reduce forces and seismic responses. The idea of controlling structures is in this perspective and in recent years, it has been used as a practical way of dealing with lateral loads made by wind and earthquakes. Structural behavior control is mainly categorizedinto three groups: passive control, active control, and semi-active control.

Among different structure control methods, inactive control is more acceptable than other control methods due to some reasons such as no need for external force, ease of installation and maintenance as well as its simple mechanism. Among the inactive control tools, the Tuned Mass Damper can be mentioned as one of the most practical tools used for structural control. Various studies have been conducted on the efficiency of these dampers in reducing seismic responses of structures, and today, the applications of different types of dampers can be observed in different parts of the world.

In most of the researches, fixed supportwas considered for the controlled structure and non-elastic behavior of the structure due to lateral loading was not included, both of which can lead to the loss of damper efficiency. Also, in the three-dimensional structures, the correct selection of damper location in the plan can make the efficiency of dampers better.

In present study, in addition to using several tuned mass dampers in orthogonal directions to control the seismic behavior of three-dimensional irregular structure models, it was tried to find the most suitable arrangement of the dampers to achieve the highest efficiency by considering non-linear behavior of the dampers. For this purpose, three-dimensional structure models were considered with the number of floors and different eccentricities of the load, as flexural steel frame with non-linear behavior. In total, 11 earthquake records have been used in present study.

The idea of using tuned mass damper was first introduced by Frahm in 1909. Subsequently, in 1928, Den Hartog \&Ormondroydhave studied non-damping and damping vibration absorber theory for a non-damping structure and presented the basics of proper selection of vibration absorber parameters. In their studies, they concluded that adding a damping to a tuned mass damper would increase its efficiency. However, they have not explained how to adjust the rigidity of system to optimizethe system frequency response. The optimal method for choosing rigidity of the tuned mass damper system was firstly studied by Erich Hahnkamm. He showed that an optimal rigidity can be chosen for a damper, for which the system has the least response [13]. 
Jeninge\&Frohribnumerically evaluated a rotary shock absorber system for controlling both torsional and flexural modes in a building structure. The experimental formulas were developed for the correction factors of the main damper parametersby Ioiand Ikeda. Design tables for these parameters when including the damping effect in the main system were presented by Randall et al..Various researchers, including Warburton, have identified the optimal values of various tuned mass damper parameters for alternative and arbitrary loads [1].

\section{Method}

- Modeling assumptions

Given that the present study aimed to investigate the tuned mass damper efficiencyin the control of seismic behavior of structures with three dimensional nonlinear behavior andsubjected to the near-fault earthquake, the used models must be such that they can indicate the effects of being three-dimensional and nonlinearity. Therefore, in selecting structure models, the following conditions must be fulfilled:

1. It represent the conventional and typicalbuilding structures, from low to high-rise buildings.

2. It has different eccentricities of the load to take into account the effects of asymmetric plan.

3. It has nonlinear behavior.

In present study, it was tried to select the models based on the above assumptions and similar to those used in previous researches $([2,9])$. In fact, it was tried to make the least changes in existing models to make them in compliance with the demands of present study in order to complete previous studies and the similarity of behavioral models makes it possible to validate the modeling.

To design the structures, the ETABS software was used and the OpenSees Software was usedfor analysis and parametric studies.

\section{- $\quad$ Structure models}

Designed models are including three 3D 4-,8- and 15-floor structure models. In all of them, the floor height is equal to 3 meters. To investigate the TMD efficiency in plan-asymmetric structures, the eccentricities of zero, 10 and $15 \%$ wereconsideredfor the above structures. These eccentricitieswere applied by simultaneously moving the mass centers of all floors and in two directions. The eccentricities are the same for all floors. In other words, the mass centers of the floors are on the vertical axis, and this axis has the eccentricity compared to the rigiditycenter of the floors (Fig. 1).

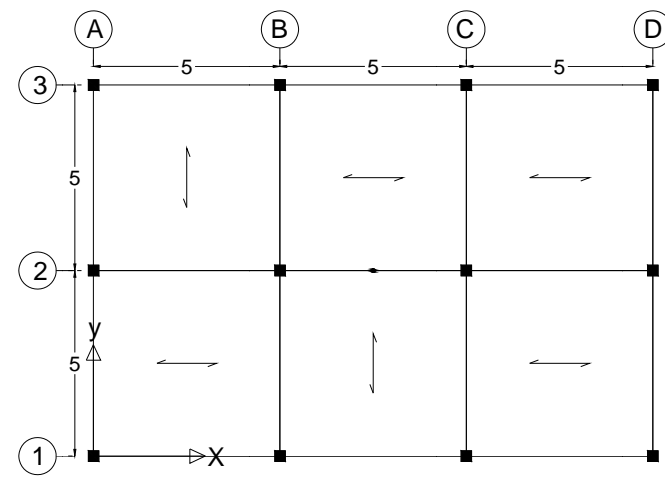

Figure 1. Typical floor plan in the structure models

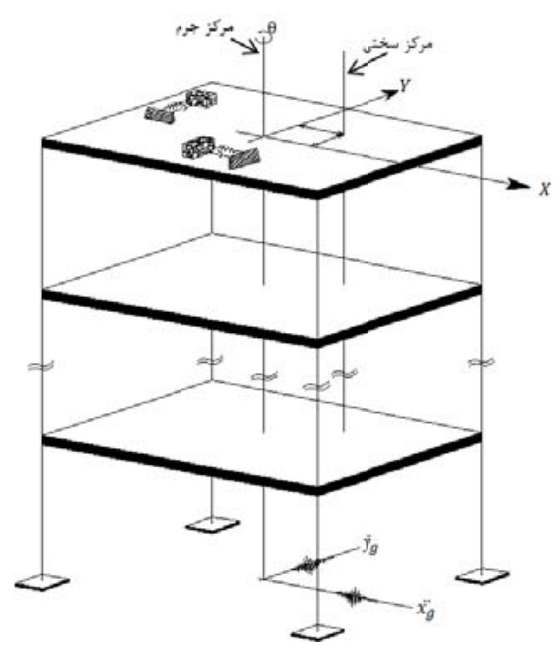

Figure 2.Schematic diagram of the studied models 
In these models, a steel flexural frame was selected as the lateral force resisting system and the bilinear strain hardening was selected asnonlinear behavior of the steel. Earthquake stimulation was appliedon the structure in two directions perpendicular to each other simultaneously. Horizontal components of an earthquake were used for bi-directional stimulation. To control the structure response, two tuned mass dampers wereplacedon the roof floor and in two directions perpendicular to each other. The damping of structure was applied to the structure as a Riley damping.

- Specifications of steel

Specifications of steel included in the modeling are as follows:

The elastic modulus: $\mathrm{E}_{\mathrm{s}}=2.04 \mathrm{e} 10 \mathrm{~kg} / \mathrm{m}^{2}$

Submission tension: $\mathrm{F}_{\mathrm{y}}=2.4 \mathrm{e} 7 \mathrm{~kg} / \mathrm{m}^{2}$

Final tension: $\mathrm{F}_{\mathrm{u}}=3.7 \mathrm{e} 7 \mathrm{~kg} / \mathrm{m}^{2}$

Poisson coefficient: $v=0.3$

The bilinear behavior of the steel with a secondary slope of 0.02 was considered as the initial slope of the stressstrain diagram (Fig. 3).

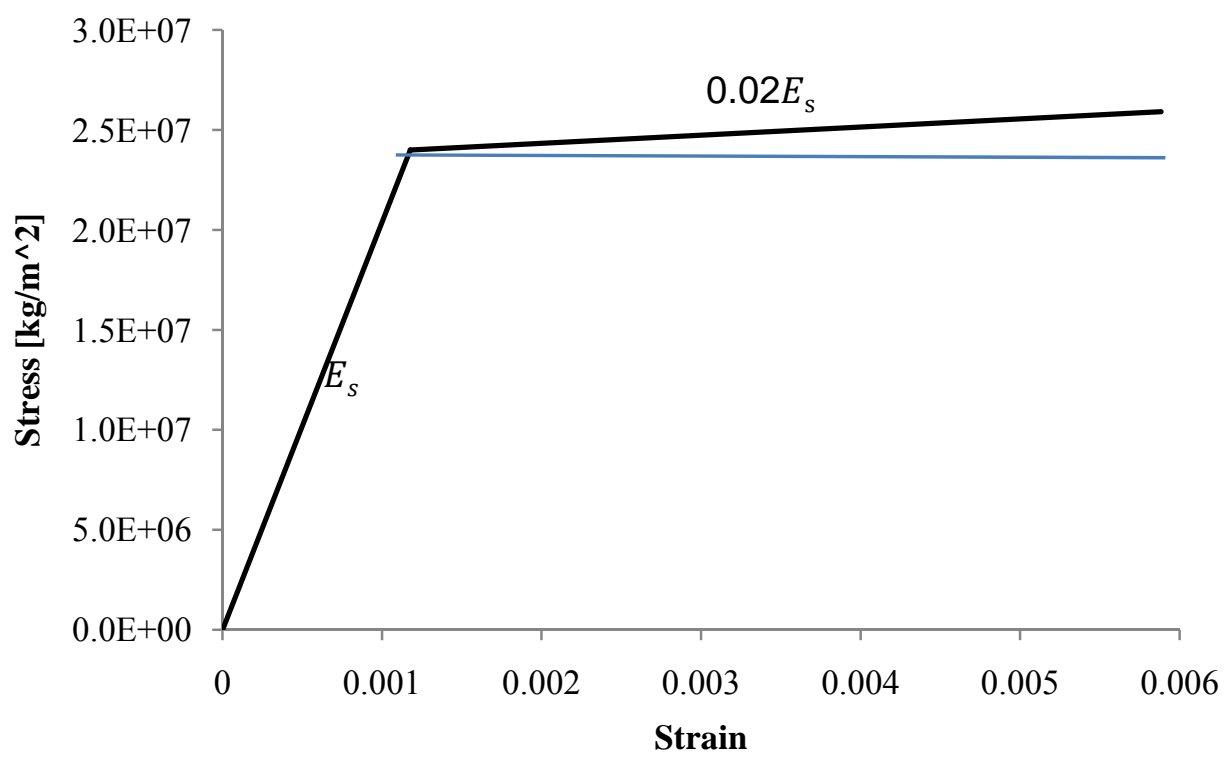

Figure 3. Stress-strain diagram of steel

- $\quad$ Structure design

The parameters considered in designingstructure models are as fallows:

- The structural system is a steel flexural frame.

- The foots of all columns are assumed to be fixed.

- The bottom of floors are rigidly molded.

- According to the usual values considered for flooring and Iranian Standard Code No.519for loading, gravitational loading is considered $600 \mathrm{~kg} / \mathrm{m}^{2}$ for dead load and $200 \mathrm{~kg} / \mathrm{m}^{2}$ for live load and $150 \mathrm{~kg}$ $/ \mathrm{m}^{2}$ live load of roof floor and it is applied in a chessboard arrangement on the floors.

- Lateral loading is performed considering the height of structures and the earthquake loading, regardless of wind load, and in accordance with the third edition of Iranian Code of Practice for Seismic Resistant Design of Buildings (known as Iran national Standard No. 2800).

Earthquake coefficient: $\quad C=\frac{A B I}{R}$

Base shear: $\mathrm{V}=\mathrm{CW}$

In the above equations, $\mathrm{C}$ is the earthquake coefficient, $\mathrm{A}$ is the design base acceleration, $\mathrm{B}$ is the building reflectionfactor, $\mathrm{I}$ is the building importance factor, $\mathrm{R}$ is the building behavior factor, $\mathrm{V}$ is the base shear and $\mathrm{W}$ is the total building weight, including the total dead load, plus $20 \%$ of the live load of building.

- Structural design is conducted according to UBC97 regulations usingAllowable Strength Design (ASD) method. 
Since the objective of present study, which is the comparison of seismic behavior of models in the controlled and uncontrolled modes, how to design and select the sections is not important and in the present study, the accuracy was considered just to make the models more realistic.

The sections used for columns are selected in hollow-square. Table 1 shows the sections of the columns used in the design of structures. For beams, the IPE section is used.

Table1. The sections of columns used in structure models

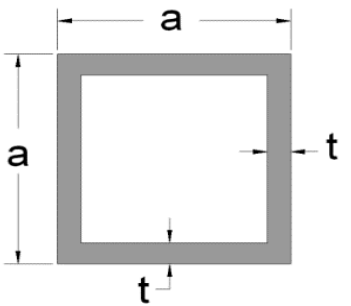

\begin{tabular}{|c|c|c|c|c|c|}
\hline Section name & $\boldsymbol{a}[\boldsymbol{m}]$ & $\boldsymbol{t}[\boldsymbol{m}]$ & $\boldsymbol{A}\left[\boldsymbol{m}^{\mathbf{2}}\right]$ & $\boldsymbol{J}\left[\boldsymbol{m}^{\mathbf{4}}\right]$ & $\boldsymbol{I}_{\boldsymbol{y}}=\boldsymbol{I}_{\boldsymbol{z}}\left[\boldsymbol{m}^{\mathbf{4}}\right]$ \\
\hline BOX300X10 & 0.3 & 0.01 & 0.0116 & 0.000244 & 0.000163 \\
\hline BOX300X15 & 0.3 & 0.015 & 0.0171 & 0.000347 & 0.000232 \\
\hline BOX300X20 & 0.3 & 0.02 & 0.0224 & 0.000439 & 0.000294 \\
\hline
\end{tabular}

- $\quad$ Specifications of tuned mass dampers

The dampers used to control the structure are placed on the roof level. To control the structure, two tuned mass dampers are used that move in two directions perpendicular to each other, and the best position of the dampers is determined by considering the different locations for TMDs. Also, using a tuned mass damper in each direction and/orusing 4 tuned mass dampers (two dampers in each direction) are considered. The coefficients $\mu$ (mass ratio), $\gamma_{\mathrm{f}}$ (frequency ratio) and $\xi_{\mathrm{TMD}}$ are as follows:

$\mu=0.02, \gamma_{\mathrm{f}}=0.98, \xi_{\mathrm{TMD}}=0.1$

In the cases of using four or one TMD, instead of two TMDs, the coefficients $\gamma_{\mathrm{f}}$ and $\xi_{\mathrm{TMD}}$ are constant, and only the coefficient $\mu$ is half and twice, respectively,compared to the use of two TMDs. In Table 2, the specifications of tuned mass dampersused in the three aforementioned cases for various structure models are listed.

Table 2. Specifications of tuned mass dampersused in thestructure models

\begin{tabular}{|c|c|c|c|c|c|c|c|c|}
\hline Model & Dir. & [kg] & {$[\mathrm{rad} / \mathrm{sec}]$} & {$[\mathrm{rad} / \mathrm{sec}]$} & $\begin{array}{l}\text { No. of } \\
\text { TMDs }\end{array}$ & {$[\mathrm{kg}]$} & {$[\mathrm{N} / \mathrm{m}]$} & {$[\mathrm{N} . \mathrm{sec} / \mathrm{m}]$} \\
\hline \multirow{6}{*}{\begin{tabular}{l}
$\geq$ \\
$\dot{0}$ \\
\multirow{\sim}{*}{} \\
$\dot{\sigma}$
\end{tabular}} & \multirow{3}{*}{$x$} & \multirow{3}{*}{328423} & \multirow{3}{*}{6.89} & \multirow{3}{*}{6.75} & 2 & 6568.46 & 299905.15 & 8876.74 \\
\hline & & & & & 4 & 3284.23 & 149952.57 & 4438.37 \\
\hline & & & & & 1 & 13136.92 & 599810.30 & 17753.48 \\
\hline & \multirow{3}{*}{$Y$} & \multirow{3}{*}{331723} & \multirow{3}{*}{7.47} & \multirow{3}{*}{7.32} & 2 & 6634.47 & 355168.42 & 9708.46 \\
\hline & & & & & 4 & 3317.235 & 177584.21 & 4854.23 \\
\hline & & & & & 1 & 13268.94 & 710336.84 & 19416.92 \\
\hline \multirow{6}{*}{ 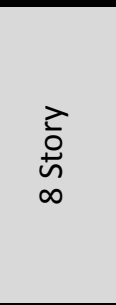 } & \multirow{3}{*}{$x$} & \multirow{3}{*}{640622} & \multirow{3}{*}{4.1} & \multirow{3}{*}{4.04} & 2 & 12812.44 & 208871.19 & 10346.30 \\
\hline & & & & & 4 & 5173.15 & 104435.60 & 6406.22 \\
\hline & & & & & 1 & 20692.60 & 417742.38 & 25624.88 \\
\hline & \multirow{3}{*}{$Y$} & \multirow{3}{*}{643121} & \multirow{3}{*}{4.39} & \multirow{3}{*}{4.32} & 2 & 11117.77 & 240243.84 & 12862.43 \\
\hline & & & & & 4 & 5558.89 & 120121.92 & 6431.22 \\
\hline & & & & & 1 & 22235.54 & 480487.68 & 25724.86 \\
\hline \multirow{6}{*}{$\begin{array}{l}7 \\
0 \\
\stackrel{2}{n} \\
\stackrel{1}{n} \\
\sim\end{array}$} & \multirow{3}{*}{$x$} & \multirow{3}{*}{1188470} & \multirow{3}{*}{2.3} & \multirow{3}{*}{2.25} & 2 & 23769.39 & 163349.48 & 12462.29 \\
\hline & & & & & 4 & 11884.70 & 81674.74 & 6231.15 \\
\hline & & & & & 1 & 47538.78 & 326698.96 & 24924.58 \\
\hline & \multirow{3}{*}{$Y$} & \multirow{3}{*}{1180493} & \multirow{3}{*}{2.43} & \multirow{3}{*}{2.38} & 2 & 23609.86 & 185731.22 & 13244 \\
\hline & & & & & 4 & 11804.93 & 92865.61 & 6622 \\
\hline & & & & & 1 & 47219.72 & 371462.44 & 26488 \\
\hline
\end{tabular}

$M_{n}^{*}$ denotes the effective mood mass of the $\mathrm{n}^{\text {th }}$ mode.

- Modeling of structures

In order to investigate both linear and nonlinear modes, structure models are first modeled nonlinearly and then, by increasing the yield tension of the steel to the appropriate value, the structure behaves linearly. 
- Records of the used earthquake

In present study, the components of 11 earthquake records were used for time history analysis. In Table 3 , the full details of these records are listed. To scale the records, in each record, the larger component was firstly scaled to a peak ground acceleration (PGA) of $0.4 \mathrm{~g}$ and then the smaller component of the earthquake is multiplied by the same scale coefficient. In order to investigate the worst occurrence of earthquake, a stronger component of the earthquake was applied to the structure in the direction in which the rigidity of the building is less (in present study, direction X).

Table 3. Specifications of the used records

\begin{tabular}{|c|c|c|c|c|c|c|c|c|c|c|}
\hline \multirow[b]{2}{*}{ No. } & \multirow{2}{*}{$\begin{array}{l}\text { Record } \\
\text { Sequence } \\
\text { Number }\end{array}$} & \multirow[b]{2}{*}{ EQID } & \multirow{2}{*}{$\begin{array}{l}\text { Earthquake } \\
\text { Name }\end{array}$} & \multirow[b]{2}{*}{ Year } & \multirow[b]{2}{*}{ Station Name } & \multirow{2}{*}{$\begin{array}{l}\text { Earthquake } \\
\text { Magnitude }\end{array}$} & \multicolumn{2}{|c|}{ Site condition } & \multicolumn{2}{|c|}{ PGA [g] } \\
\hline & & & & & & & USGS & Description & $\begin{array}{c}X \\
\text { Dir. }\end{array}$ & $\begin{array}{c}Y \\
\text { Dir. }\end{array}$ \\
\hline 1 & 830 & $\underline{\mathrm{P} 0810}$ & $\begin{array}{c}\text { Cape } \\
\text { Mendocino }\end{array}$ & 1992 & $\begin{array}{c}\text { Rio Dell } \\
\text { Overpass - FF }\end{array}$ & 7.1 & B & $\begin{array}{l}\text { Shallow } \\
\text { (stiff) soil }\end{array}$ & 0.549 & 0.385 \\
\hline 2 & 753 & P0548 & $\begin{array}{c}\text { Chalfant } \\
\text { Valley }\end{array}$ & 1986 & $\begin{array}{l}\text { Zack Brothers } \\
\text { Ranch }\end{array}$ & 5.9 & D & $\begin{array}{c}\text { Deep broad } \\
\text { soil }\end{array}$ & 0.285 & 0.207 \\
\hline 3 & 450 & $\underline{P} 1136$ & Chi-Chi & 1999 & CHY029 & 7.6 & B & $\begin{array}{l}\text { Shallow } \\
\text { (stiff) soil }\end{array}$ & 0.277 & 0.238 \\
\hline 4 & 143 & $\underline{\mathrm{P} 0140}$ & Tabas, Iran & 1978 & Dayhook & 7.4 & B & $\begin{array}{l}\text { Shallow } \\
\text { (stiff) soil }\end{array}$ & 0.406 & 0.328 \\
\hline 5 & 396 & $\underline{\mathrm{P} 1054}$ & Kobe & 1995 & Shin-Osaka & 6.9 & D & $\begin{array}{c}\text { Deep broad } \\
\text { soil }\end{array}$ & 0.243 & 0.212 \\
\hline 6 & 68 & $\underline{\mathrm{P} 0078}$ & $\begin{array}{c}\text { San } \\
\text { Fernando }\end{array}$ & 1971 & $\begin{array}{c}\text { Lake Hughes } \\
\# 12\end{array}$ & 6.6 & B & $\begin{array}{c}\text { Shallow } \\
\text { (stiff) soil }\end{array}$ & 0.366 & 0.283 \\
\hline 7 & 6 & $\underline{\mathrm{P} 0166}$ & $\begin{array}{c}\text { Imperial } \\
\text { Valley }\end{array}$ & 1979 & Chihuahua & 6.5 & C & $\begin{array}{c}\text { Deep narrow } \\
\text { soil }\end{array}$ & 0.27 & 0.254 \\
\hline 8 & 317 & $\underline{\mathrm{P} 0034}$ & Parkfield & 1966 & $\begin{array}{c}\text { Temblor pre- } \\
1969 \\
\end{array}$ & 6.1 & B & $\begin{array}{l}\text { Shallow } \\
\text { (stiff) soil }\end{array}$ & 0.357 & 0.272 \\
\hline 9 & 178 & $\underline{\mathrm{P} 0516}$ & $\begin{array}{l}\text { N. Palm } \\
\text { Springs }\end{array}$ & 1986 & Cabazon & 6.0 & D & $\begin{array}{c}\text { Deep broad } \\
\text { soil }\end{array}$ & 0.217 & 0.216 \\
\hline 10 & 808 & $\underline{\mathrm{P} 1087}$ & $\begin{array}{c}\text { Kocaeli, } \\
\text { Turkey } \\
\end{array}$ & 1999 & Arcelik & 7.4 & B & $\begin{array}{l}\text { Shallow } \\
\text { (stiff) soil }\end{array}$ & 0.218 & 0.149 \\
\hline 11 & 760 & $\underline{\text { P0889 }}$ & Northridge & 1994 & $\begin{array}{l}\text { Beverly Hills - } \\
12520 \text { Mulhol }\end{array}$ & 6.7 & B & $\begin{array}{l}\text { Shallow } \\
\text { (stiff) soil }\end{array}$ & 0.617 & 0.444 \\
\hline
\end{tabular}

Three models of 4-, 8- and 15-storey structures were studied. Due to spatiallimitations, only the specifications of 15 -story structure model are presented.

\section{5-storey structure model}

The results of analyzes performed on the linear and nonlinear 15-storey structures in the three modes of without eccentricity and eccentricities of $10 \%$ and $15 \%$ are presented below. First, the investigation of optimization based on the reduction of maximum response in linear and nonlinear modes and then, the investigation of optimization based on the reduction of maximum base and storey shearare presented.

\section{15-storey structure model without eccentricity}

\subsection{Optimization based on the reduction in maximum responses}

\subsubsection{Linear Mode}

Figure 4 shows the structure response with linear behavior on different floors, as well as in different directions, in uncontrolled mode. Figure 5 shows these responses for different positions of dampers and, finally, in Table 4, the reductions in responses arelisted in percentage. 


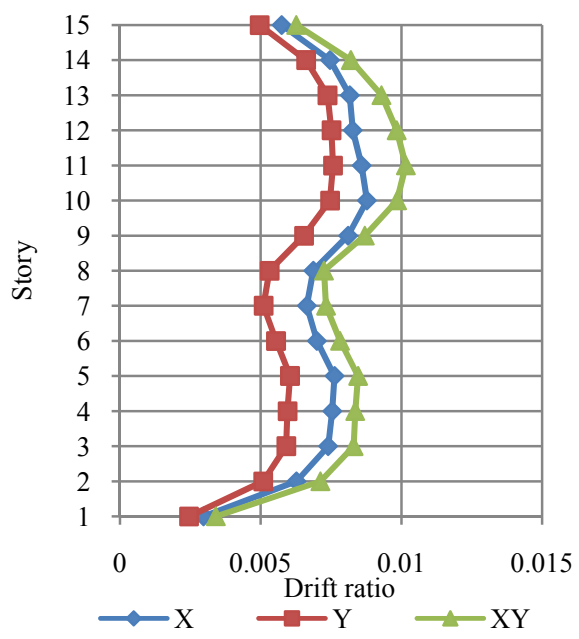

Figure 4. The maximum drift ratio for a linear 15-storey structure in uncontrolled mode (without eccentricity)
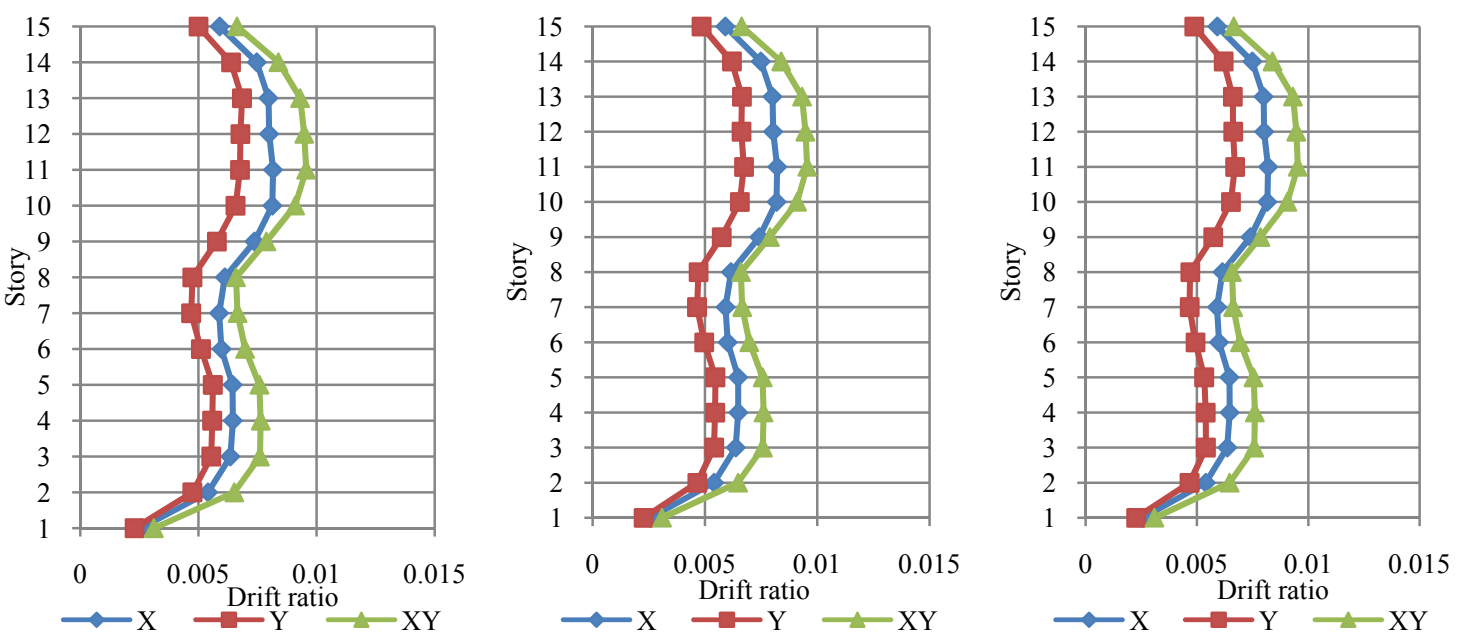

Position A1 Position A3 Position B2
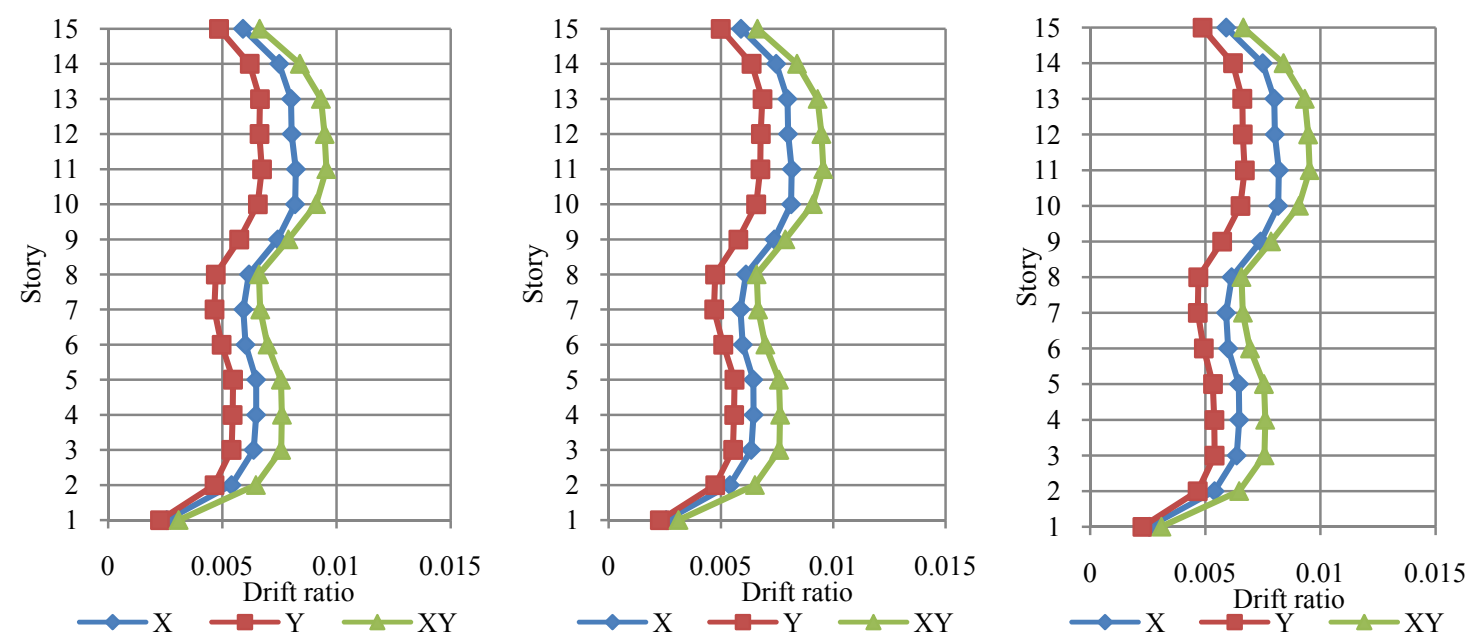

Position C1 position C3 Use of 4 dampers (4TMD) 

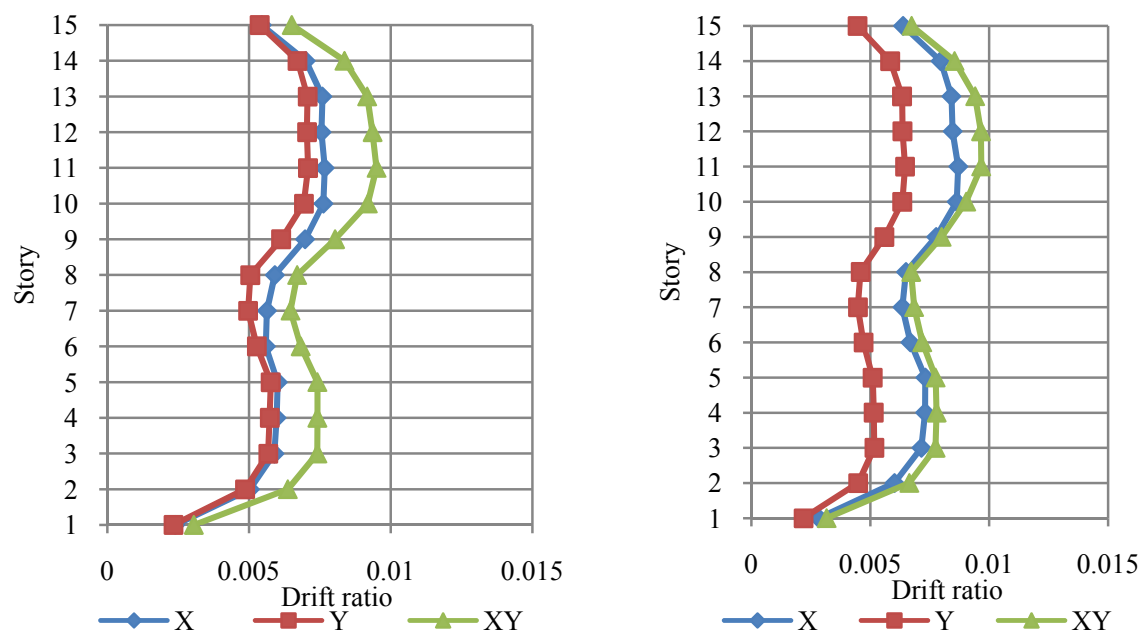

Use of a damper in direction X (TMDX)Use of a damper in directionY (TMDY)

Figure5.The maximum drift ratio for a linear 15-storey structure in uncontrolled mode (without eccentricity)and different positions of TMDs

Table 4: The reduction inmaximum responses (in percentage) in the linear 15-storey structure model without eccentricity

\begin{tabular}{|c|c|c|c|}
\hline \multirow{2}{*}{ TMD Pos. } & \multicolumn{3}{|c|}{ Reduction (\%) } \\
\cline { 2 - 4 } & $\mathrm{X}$ & $\mathrm{Y}$ & $\mathrm{XY}$ \\
\hline TMD4 & 6.99 & 12.65 & 6.21 \\
\hline TMDX & 13.12 & 7.13 & 6.45 \\
\hline TMDY & 1.63 & 14.93 & 4.81 \\
\hline A1 & 7.42 & 11.96 & 5.87 \\
\hline A3 & 6.68 & 12.22 & 5.92 \\
\hline B2 & 6.99 & 12.65 & 6.21 \\
\hline C1 & 6.68 & 12.22 & 5.92 \\
\hline C3 & 7.42 & 11.96 & 5.87 \\
\hline
\end{tabular}

According to Table 4, the greatest reduction in the maximum actual relative displacement of the structure occurred in TMDX mode.

\subsubsection{Nonlinear mode}

Figure 6 shows the structure response with non-linear behavior on different floors, as well as in different directions, in uncontrolled mode. Figure 7 shows these responses for different positions of dampers and, finally, in Table 18-6, the reductionsin responses arelisted in percentage.

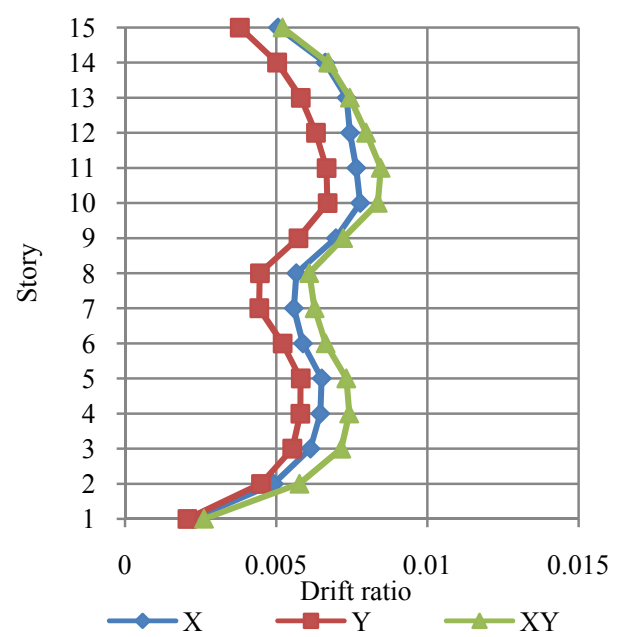

Figure6. The maximum drift ratio forthe non-linear 15-storey structure in theuncontrolled mode (without eccentricity) 

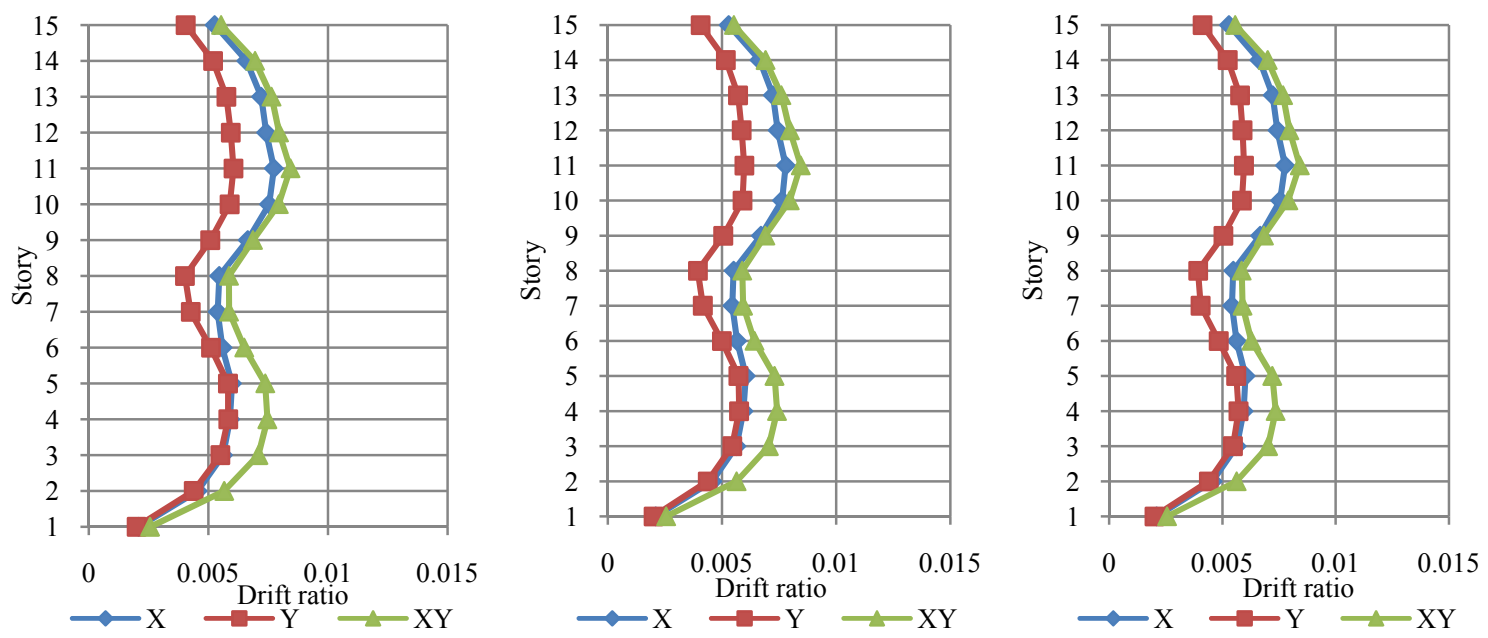

Position A1 Position A3 Position B2
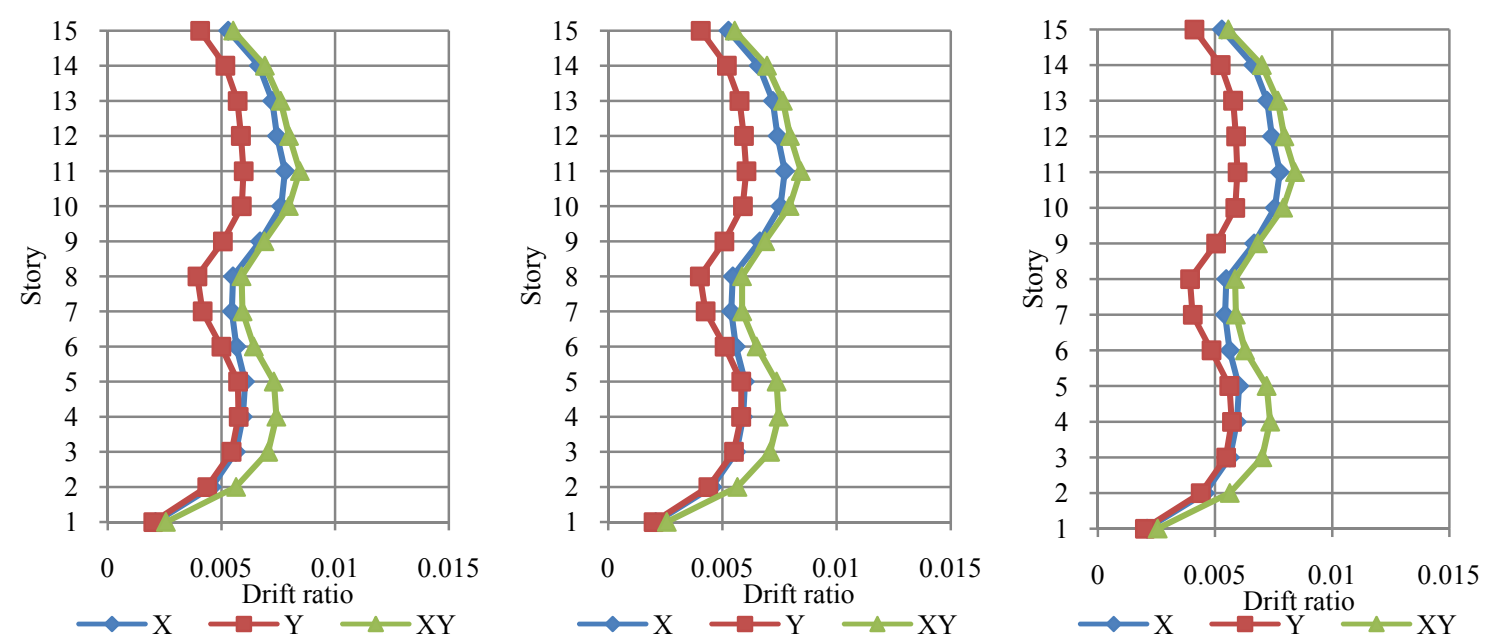

Position $\mathrm{C} 1$ position $\mathrm{C} 3$ use of 4 dampers (4TMD)
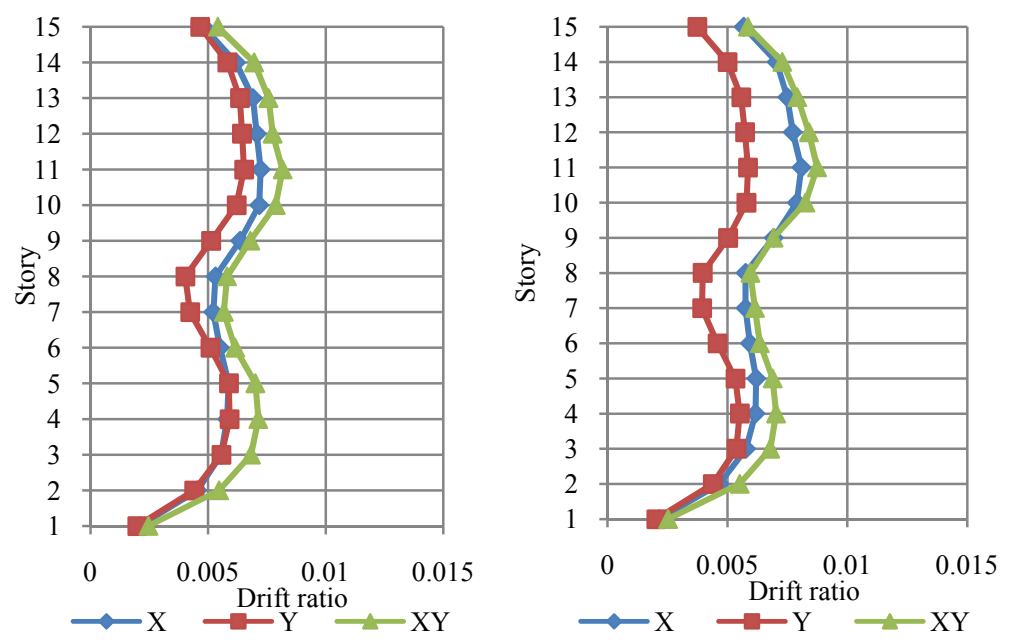

Use of a damper in direction X (TMDX)Use of a damper in directionY (TMDY)

Figure 7. The maximum drift ratio for a non-linear 15-storey(without eccentricity) in different positions of TMDs 
Table 5: Reduction in maximum responses in the non-linear 15-storey structure model without eccentricity

\begin{tabular}{|c|c|c|c|}
\hline \multirow{2}{*}{ TMD Pos. } & \multicolumn{3}{|c|}{ Reduction (\%) } \\
\cline { 2 - 4 } & $\mathrm{X}$ & $\mathrm{Y}$ & $\mathrm{XY}$ \\
\hline TMD4 & 2.92 & 12.46 & 0.48 \\
\hline TMDX & 7.79 & 7.26 & 3.43 \\
\hline TMDY & -1.48 & 13.45 & -3.36 \\
\hline A1 & 3.07 & 11.97 & 0.25 \\
\hline A3 & 1.94 & 11.95 & 0.09 \\
\hline B2 & 2.92 & 12.46 & 0.48 \\
\hline C1 & 1.99 & 11.95 & 0.11 \\
\hline C3 & 3.05 & 11.97 & 0.28 \\
\hline
\end{tabular}

According to Fig. 8, by comparing two linear and nonlinear modes, it is observed that in the nonlinear mode, the damper efficiency decreased.

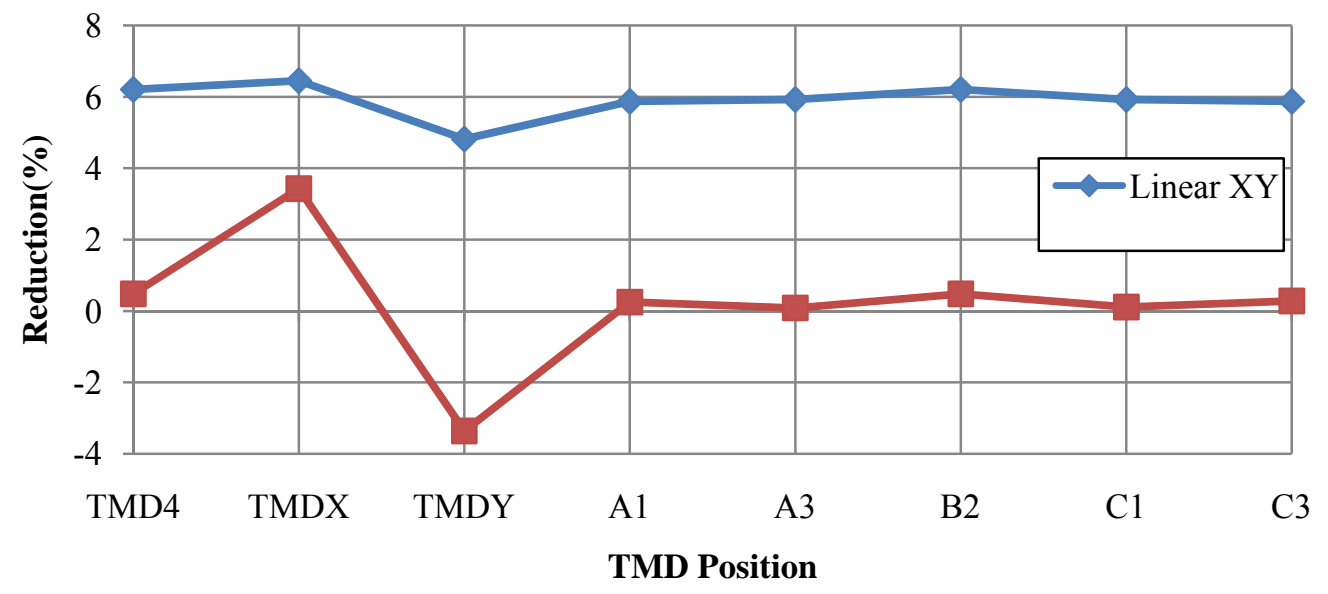

Figure 8. Comparison of the percentage of reduction in the maximum actual response of the 15-story structure model without eccentricityin two linear and nonlinear modes

\subsection{Optimization based on the reduction in maximum base and storey shear}

\subsubsection{Linear Mode}

In Fig. 9, maximum storey shearin uncontrolled mode is shown and in Fig.10,it is shown in different positions of dampers.In Fig. 11, the maximum base shearis shown in different TMD positionsin the linear model without eccentricity and in Table 6, reduction in base shear, as well as reduction instorey shear for that floor on which the greatest relative displacement occurred, i.e. the second floor, are listed in percentage. 


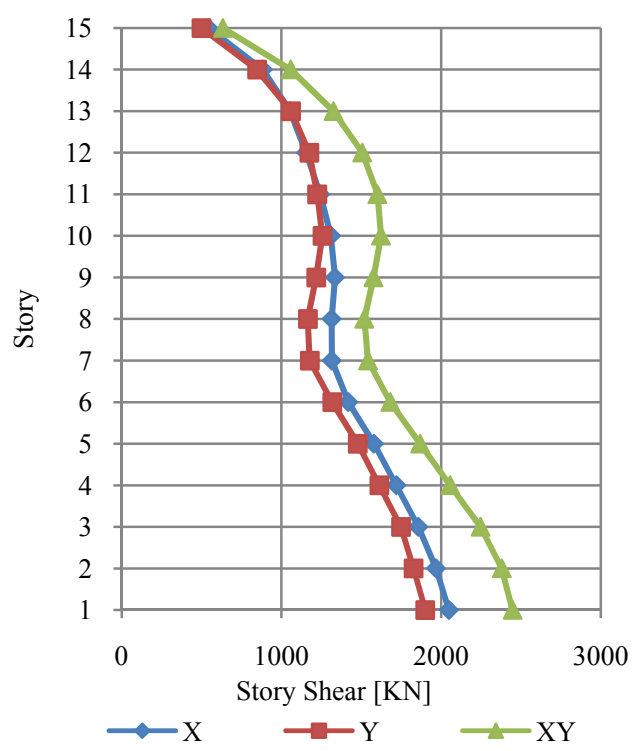

Figure 9. Maximum storey shearin thelinear 15-story structure model in the uncontrolled mode (without eccentricity)
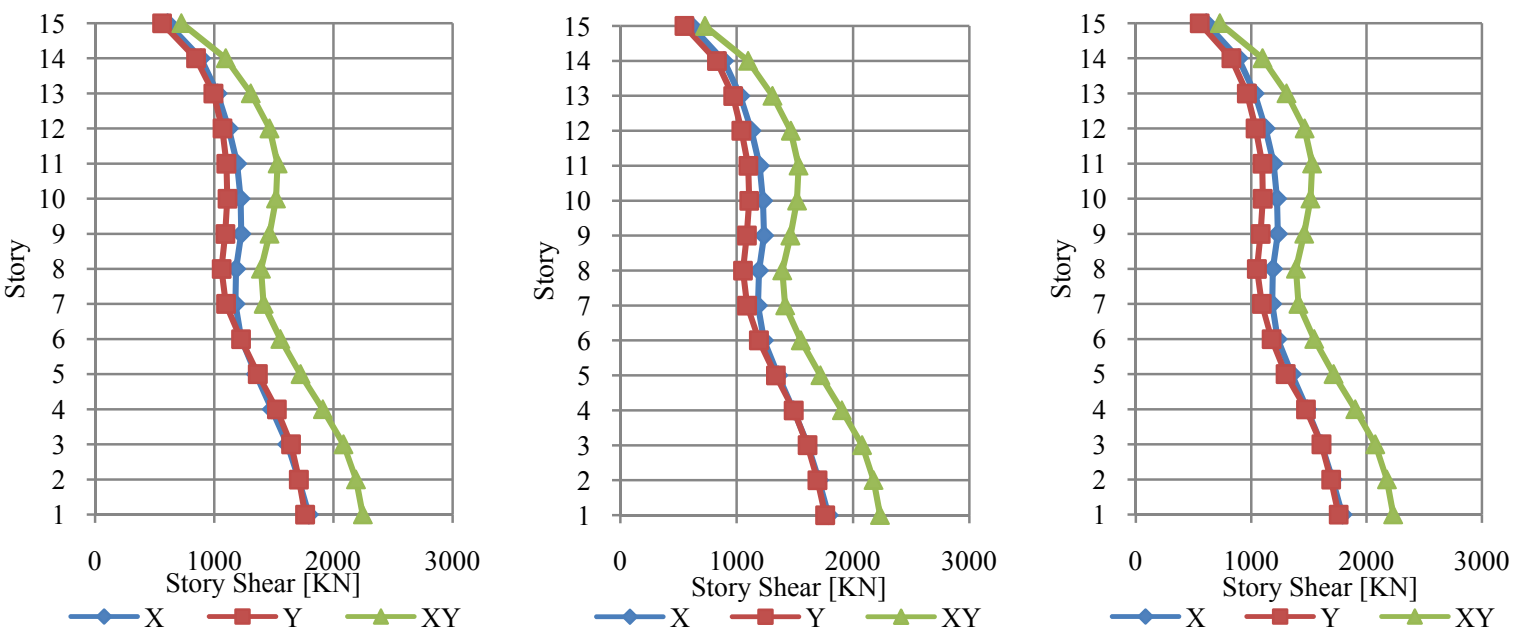

Position A1 Position A3 Position B2
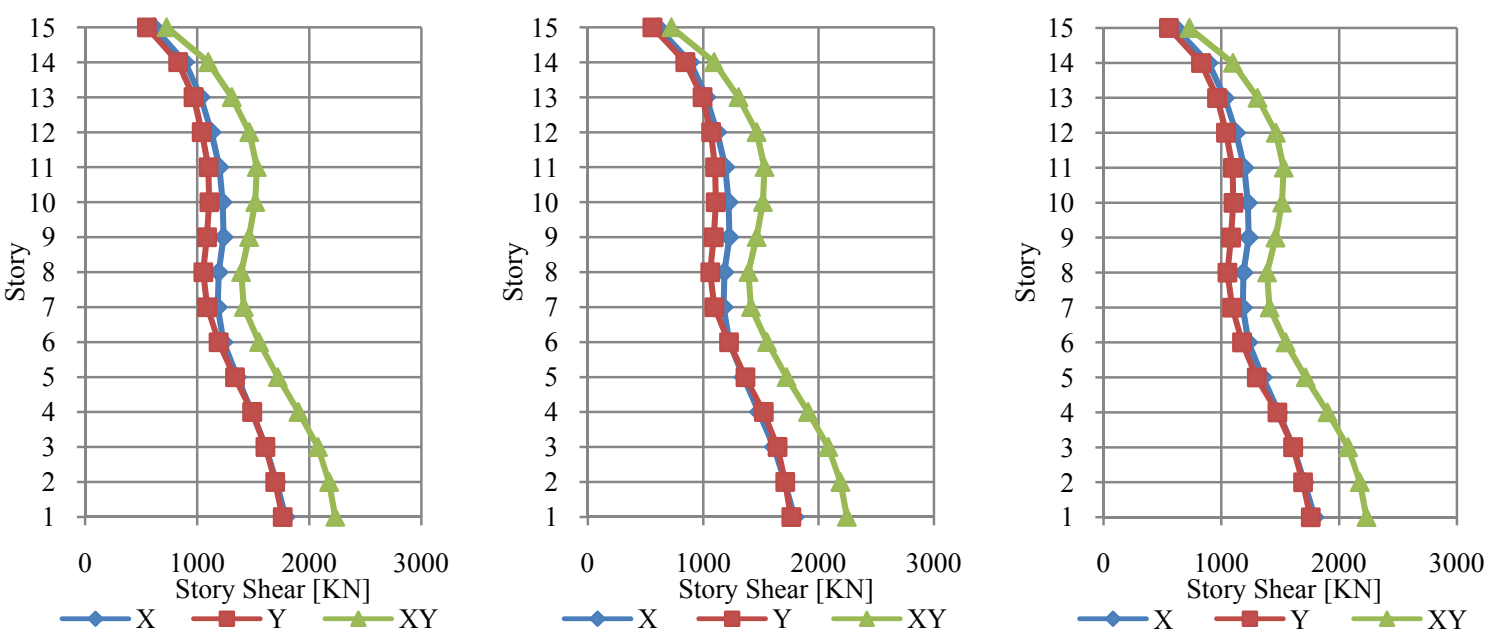

Position $\mathrm{C} 1$ position $\mathrm{C} 3$ use of 4 dampers (4TMD)

Use of a damper in direction X (TMDX)Use of a damper in directionY (TMDY)

Figure 10. Maximum storey shear inthe linear 15-story structure model (without eccentricity) in different TMD positions 


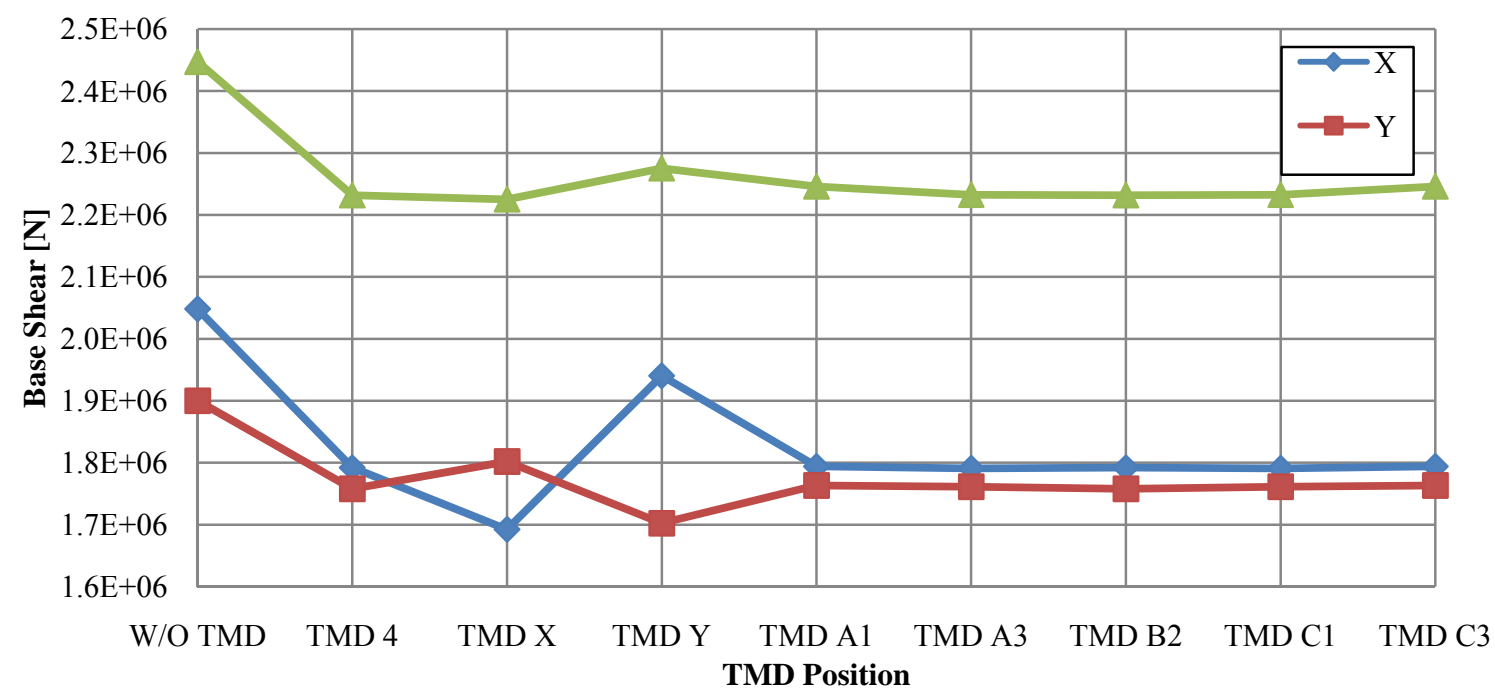

Figure 11: Maximum base shearin different TMD positions in the linear 15-story structure model without eccentricity Table 6: Reduction in base shear and the second storey shearin linear 15-storey structure model without eccentricity (in percentage)

\begin{tabular}{|c|c|c|c|c|c|c|}
\hline \multirow{2}{*}{ TMD Pos. } & \multicolumn{4}{|c|}{ Base Shear Reduction (\%) } & \multicolumn{4}{|c|}{ 11th Story Shear Reduction (\%) } \\
\cline { 2 - 7 } & $\mathrm{X}$ & $\mathrm{Y}$ & $\mathrm{XY}$ & $\mathrm{X}$ & $\mathrm{Y}$ & $\mathrm{XY}$ \\
\hline TMD4 & 12.50 & 7.48 & 8.80 & 3.80 & 10.49 & 4.51 \\
\hline TMDX & 17.37 & 5.16 & 9.08 & 9.58 & 6.31 & 5.06 \\
\hline TMDY & 5.27 & 10.41 & 7.03 & -0.41 & 12.86 & 3.62 \\
\hline A1 & 12.41 & 7.20 & 8.23 & 4.09 & 9.98 & 4.39 \\
\hline A3 & 12.56 & 7.30 & 8.78 & 3.62 & 10.19 & 4.36 \\
\hline B2 & 12.50 & 7.48 & 8.80 & 3.80 & 10.49 & 4.51 \\
\hline C1 & 12.56 & 7.30 & 8.78 & 3.62 & 10.19 & 4.35 \\
\hline C3 & 12.41 & 7.20 & 8.23 & 4.09 & 9.98 & 4.39 \\
\hline
\end{tabular}

\subsubsection{Nonlinear mode}

In Fig. 12, maximum storey shearin uncontrolled mode is shown and in Fig.13,it is shown in different positions of dampers. In Fig. 14, the maximum base shearis shown in different TMD positionsin the non-linear model without eccentricity and in Table 7, reduction in base shear, as well as reduction instorey shear for that floor on which the greatest relative displacement occurred, i.e. the sixth floor, are listed in percentage.

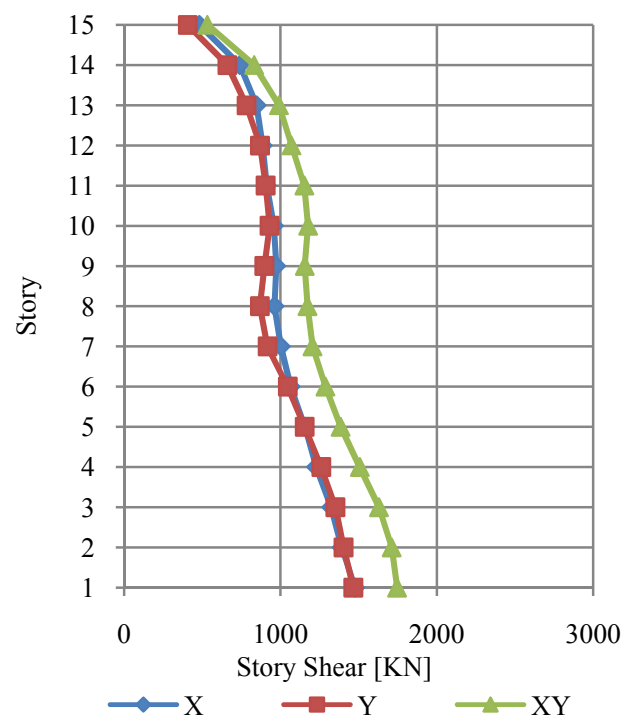

Figure 12.Maximum storey shearinthenon-linear 15-story structure model in the uncontrolled mode (without eccentricity) 

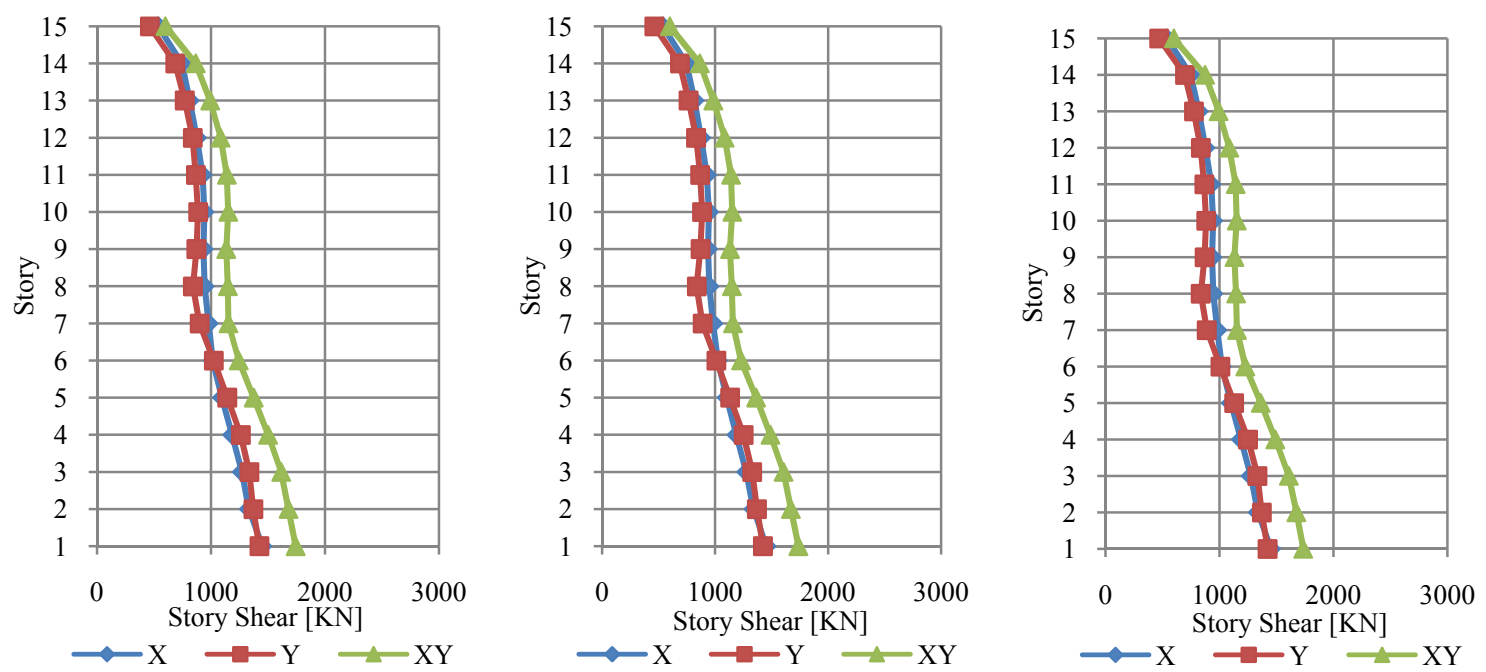

Position A1 Position A3 Position B2
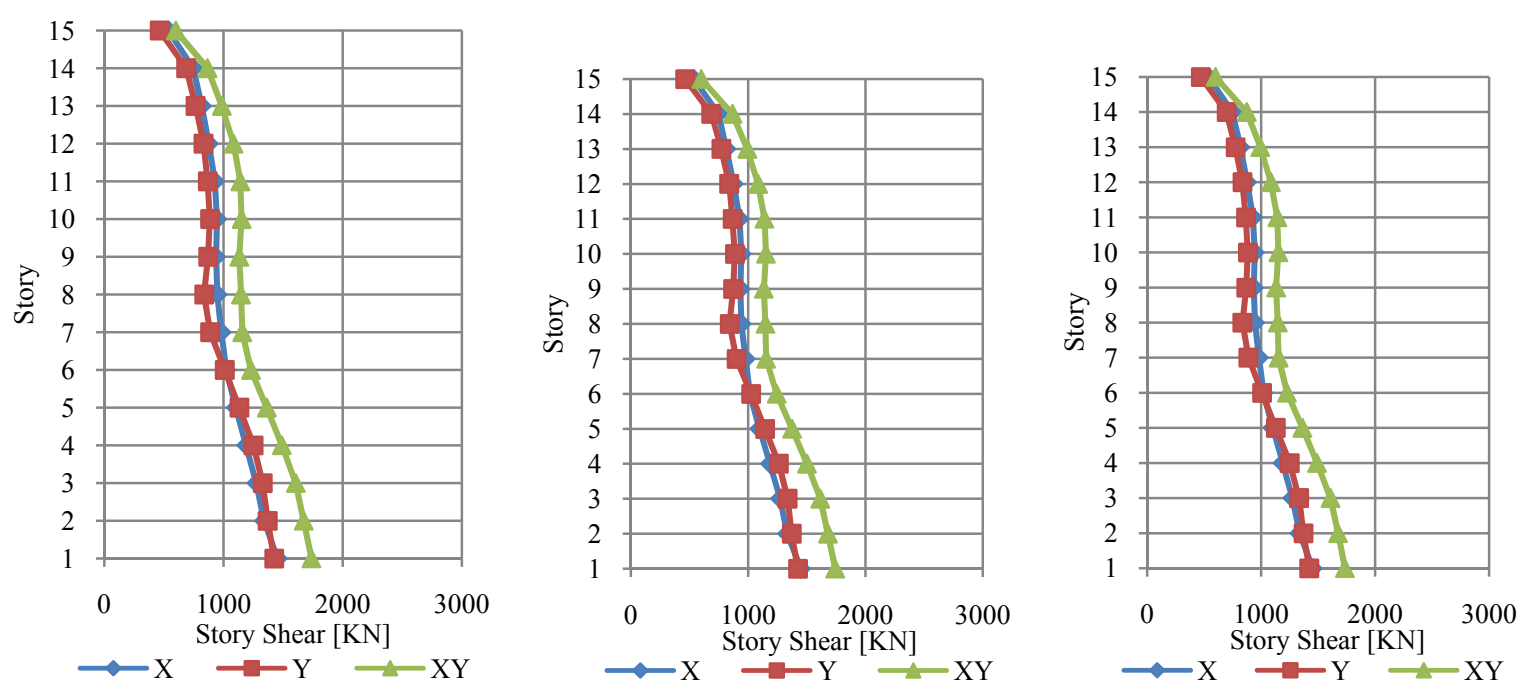

Position $\mathrm{C} 1$ position $\mathrm{C} 3$ use of 4 dampers (4TMD)

Use of a damper in direction X (TMDX)Use of a damper in directionY (TMDY)

Figure 13. Maximum storey shear inthenon-linear 15-story structure model (without eccentricity) in different TMD positions

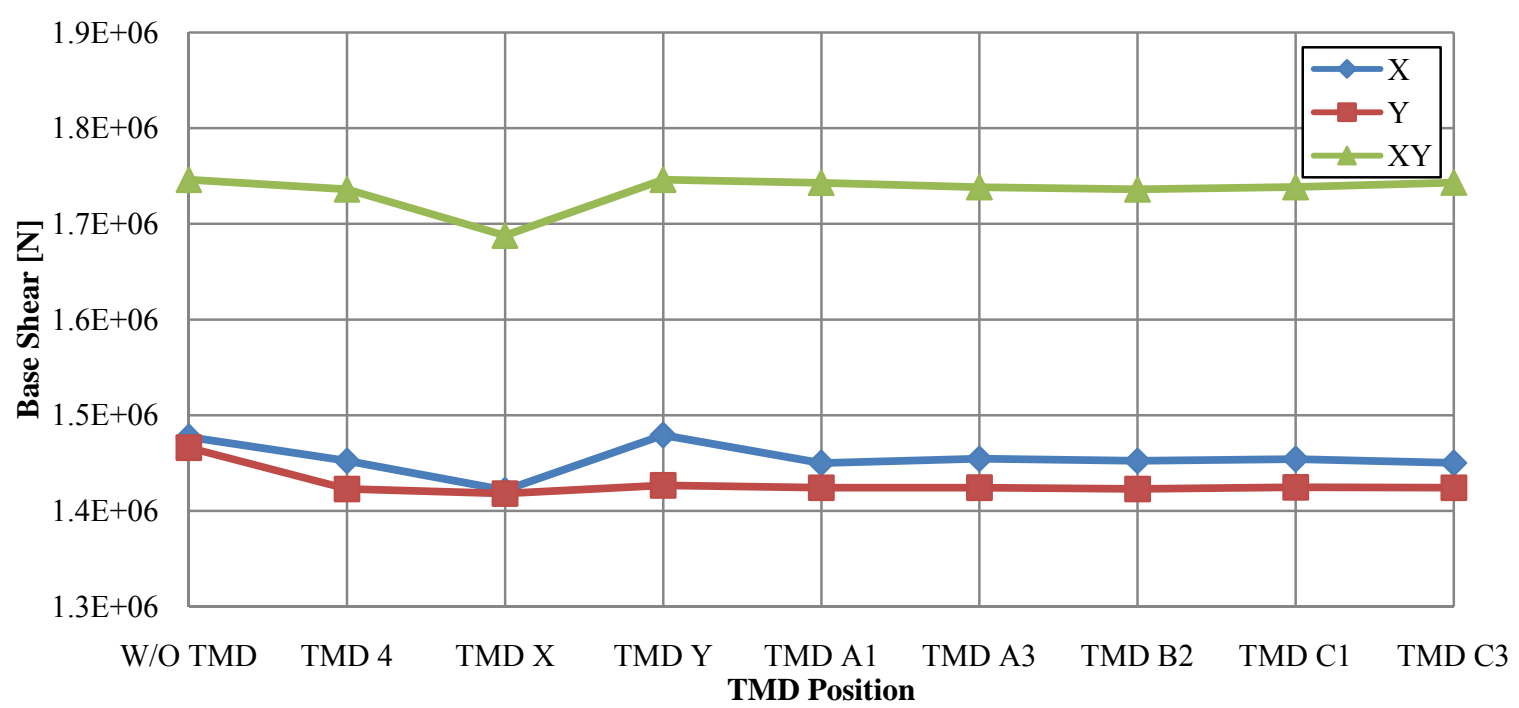

Figure 14: Maximum base shearin different TMD positions in the non-linear 15-story structure model without eccentricity 
Table 7: Reduction in base shear and thesixthstorey shearin the non-linear 15-storey structure model without eccentricity (in percentage)

\begin{tabular}{|c|c|c|c|c|c|c|}
\hline \multirow{2}{*}{ TMD Pos. } & \multicolumn{3}{|c|}{ Base Shear Reduction (\%) } & \multicolumn{3}{|c|}{ 11th Story Shear Reduction (\%) } \\
\cline { 2 - 7 } & $\mathrm{X}$ & $\mathrm{Y}$ & $\mathrm{XY}$ & $\mathrm{X}$ & $\mathrm{Y}$ & $\mathrm{XY}$ \\
\hline TMD4 & 1.69 & 2.95 & 0.58 & -1.67 & 4.32 & 0.86 \\
\hline TMDX & 3.77 & 3.27 & 3.34 & 1.83 & 0.09 & 0.35 \\
\hline TMDY & -0.13 & 2.68 & 0.00 & -3.07 & 4.32 & 0.94 \\
\hline A1 & 1.85 & 2.86 & 0.18 & -1.49 & 4.34 & 1.18 \\
\hline A3 & 1.54 & 2.85 & 0.44 & -1.74 & 4.19 & 0.93 \\
\hline B2 & 1.69 & 2.95 & 0.58 & -1.67 & 4.32 & 0.86 \\
\hline C1 & 1.56 & 2.83 & 0.44 & -1.74 & 4.20 & 0.94 \\
\hline C3 & 1.84 & 2.85 & 0.17 & -1.48 & 4.35 & 1.18 \\
\hline
\end{tabular}

In Figures 15 and 16 , percentage of the reduction in the actual base shear and the actual $6^{\text {th }}$ storey shear are shown for both linear and nonlinear modes. As can be seen, the damper efficiency in nonlinear mode is reduced compared to linear mode. Also, the sensitivity of the structure behavior to the position of TMDs in the nonlinear mode is less.

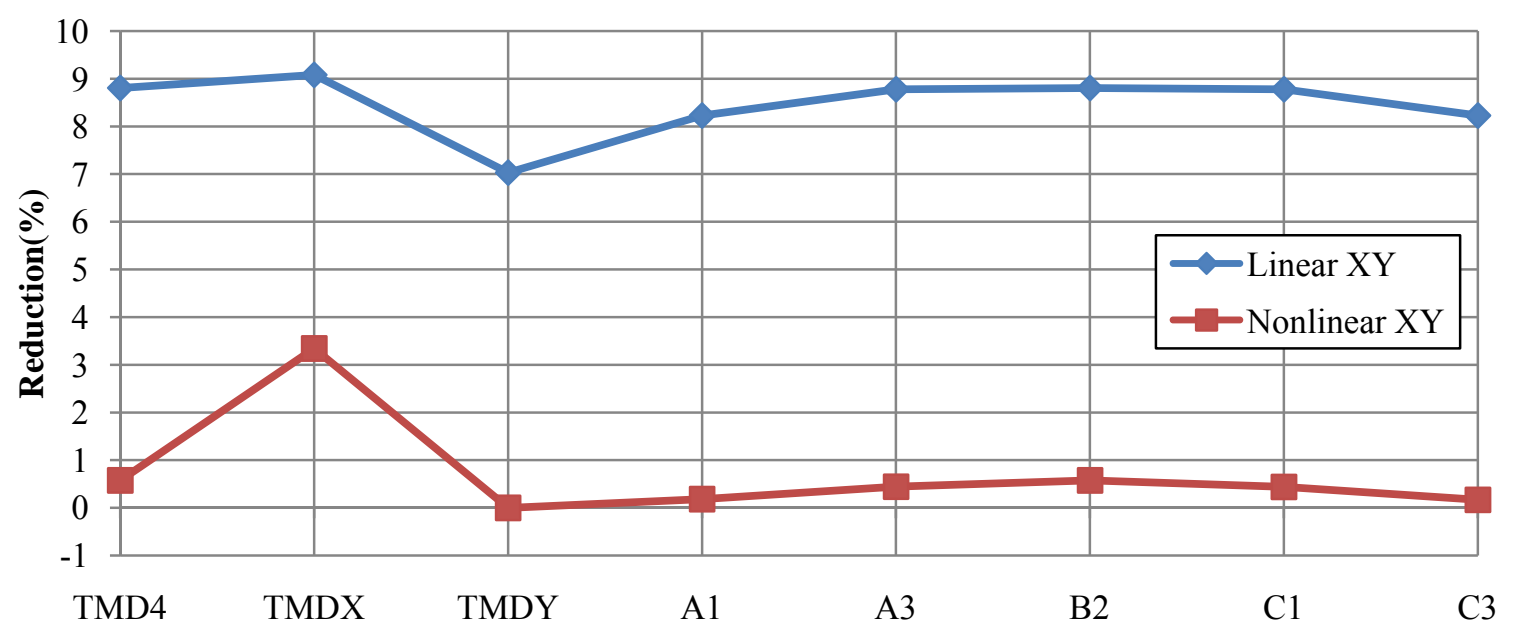

TMD Position

Figure 15. Comparison of the percentage of reduction in the actual base shear in the 15 -storey structure model without eccentricity in two linear and nonlinear modes

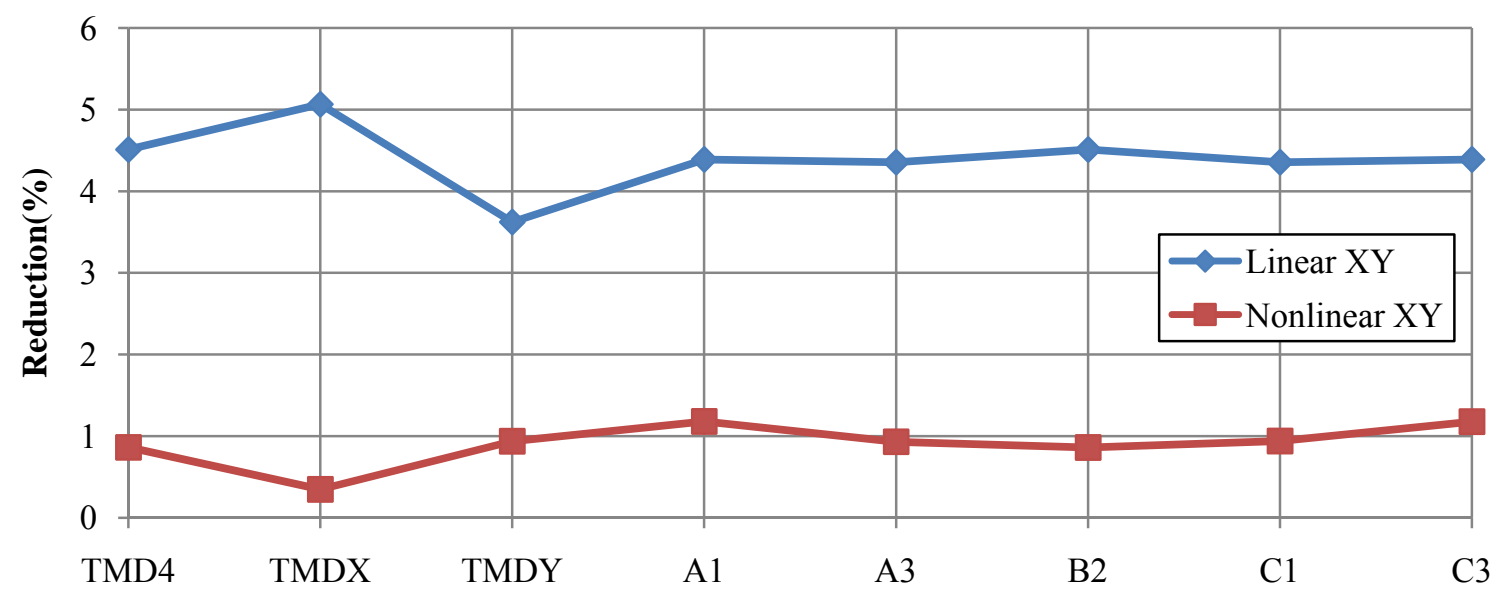

TMD Position

Fig. 16. Comparison of the percentage of reduction in the actual second storey shear in the 15 -storey structure model without eccentricity in two linear and nonlinear modes 


\section{The 15-storey structure model with eccentricities of $10 \%$ and $15 \%$}

\subsection{Optimization based on the reduction in maximum responses}

\subsubsection{Linear Mode}

Table 8 shows the reduction in maximum responses in the15-storey structure with linear behavior and for eccentricities of $10 \%$ and $15 \%$ in percentage.

Table8. Reduction in maximum responses in the linear 15 -storey structure model with eccentricities of $10 \%$ and $15 \%$ (in percentage)

\begin{tabular}{|c|c|c|c|c|c|c|c|c|}
\hline \multirow{2}{*}{ TMD Pos. } & \multicolumn{9}{|c|}{ Reduction (\%) } \\
\cline { 2 - 9 } & \multicolumn{3}{|c|}{ Ecc.10\% } & \multicolumn{4}{c|}{ Ecc.15\% } \\
\cline { 2 - 9 } & $\mathrm{X}$ & $\mathrm{Y}$ & $\mathrm{XY}$ & $\boldsymbol{\theta}$ & $\mathrm{X}$ & $\mathrm{Y}$ & $\mathrm{XY}$ & $\boldsymbol{\theta}$ \\
\hline TMD4 & 7.02 & 1.53 & 6.84 & 18.94 & 7.37 & -0.98 & 6.28 & 9.39 \\
\hline TMDX & 10.28 & 0.94 & 10.68 & 9.11 & 8.62 & -1.15 & 7.88 & 8.86 \\
\hline TMDY & 3.22 & 0.87 & 5.91 & 10.54 & 6.10 & -2.94 & 3.20 & 1.35 \\
\hline A1 & 4.69 & -1.10 & 4.58 & 21.27 & 4.54 & -3.70 & 3.76 & 12.49 \\
\hline A3 & 7.93 & -1.43 & 7.04 & 19.26 & 8.50 & 0.17 & 6.51 & 8.16 \\
\hline B2 & 6.41 & 3.18 & 6.87 & 9.41 & 6.61 & -2.43 & 5.89 & 4.34 \\
\hline C1 & 5.68 & -0.51 & 7.15 & 15.58 & 5.83 & 0.58 & 4.71 & 10.53 \\
\hline C3 & 9.16 & 1.66 & 9.04 & 13.09 & 9.46 & -0.36 & 8.10 & 6.79 \\
\hline
\end{tabular}

As shown in Table 8, the greatest reduction in the maximum actual structure displacement, for both eccentricities, was obtained in TMDX and C3.

\subsubsection{Nonlinear mode}

Table 9 shows the reduction in maximum responses in the15-storey structure with non-linear behavior and for eccentricities of $10 \%$ and $15 \%$ in percentage.

Table8. Reduction in maximum responses in the non-linear 15 -storey structure model with eccentricities of $10 \%$ and $15 \%$ (in percentage)

\begin{tabular}{|c|c|c|c|c|c|c|c|c|}
\hline \multirow{2}{*}{ TMD Pos. } & \multicolumn{9}{|c|}{ Reduction (\%) } \\
\cline { 2 - 9 } & \multicolumn{3}{|c|}{ Ecc.10\% } & \multicolumn{4}{c|}{ Ecc.15\% } \\
\cline { 2 - 10 } & $\mathrm{X}$ & $\mathrm{Y}$ & $\mathrm{XY}$ & $\boldsymbol{\theta}$ & $\mathrm{X}$ & $\mathrm{Y}$ & $\mathrm{XY}$ & $\boldsymbol{\theta}$ \\
\hline TMD4 & 3.81 & 2.68 & 1.48 & 17.00 & 2.70 & -3.62 & 0.79 & 12.67 \\
\hline TMDX & 3.95 & 2.19 & 6.15 & 12.52 & 2.36 & -1.56 & 2.79 & 9.94 \\
\hline TMDY & 1.38 & 6.10 & -1.33 & 8.46 & 0.23 & -2.91 & -0.36 & 2.32 \\
\hline A1 & 3.32 & 4.36 & 1.23 & 20.79 & 0.29 & -3.01 & 0.27 & 17.20 \\
\hline A3 & 3.67 & 2.80 & 3.38 & 18.79 & 3.29 & -2.89 & 2.02 & 14.79 \\
\hline B2 & 3.06 & 3.63 & 1.65 & 9.60 & 1.87 & -2.17 & 0.55 & 7.30 \\
\hline C1 & 3.14 & 3.10 & -0.54 & 14.62 & 1.14 & -2.68 & -0.19 & 7.12 \\
\hline C3 & 4.00 & 1.90 & 1.14 & 7.48 & 3.24 & -3.80 & 1.32 & 6.67 \\
\hline
\end{tabular}

According to Table 10, the maximum reduction in the maximum actual relative displacement of nonlinear structure with an eccentricity was achieved in TMDX. In figures 17 and 18, percentage of reduction in the maximum actual response of the structure for the eccentricities of $10 \%$ and $15 \%$ and in different damper positions in the two linear and nonlinear modes are shown. 


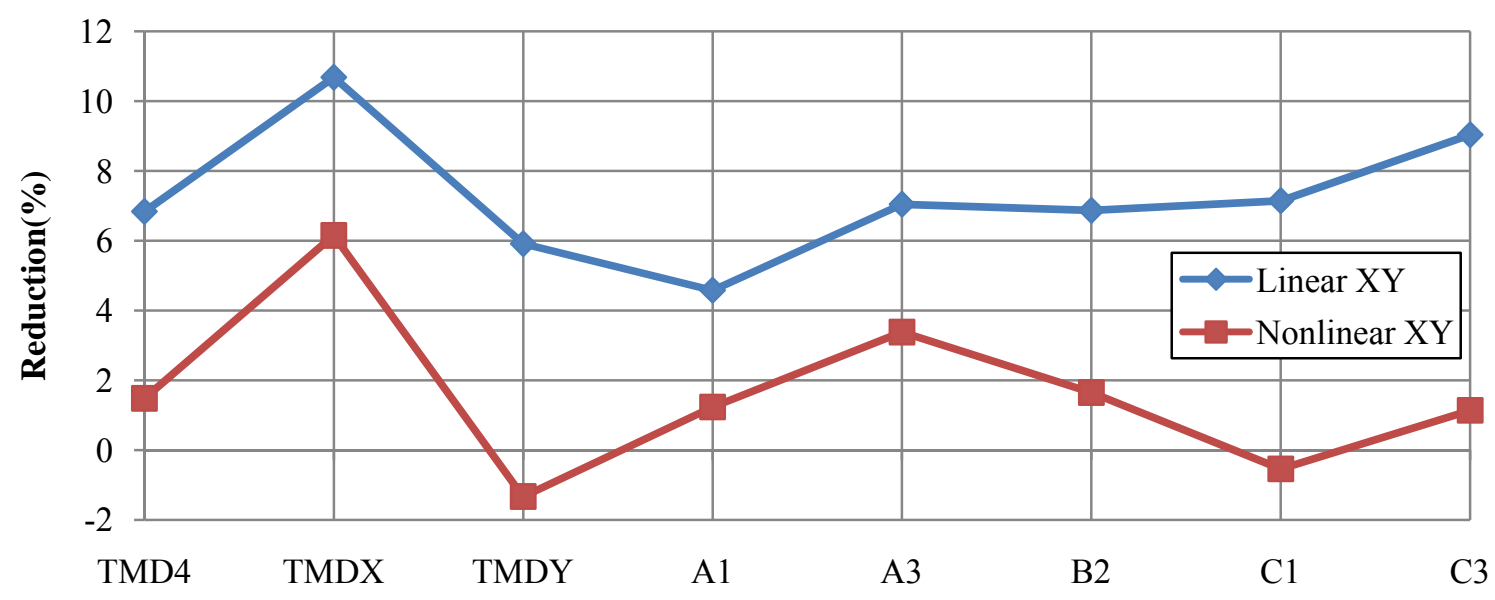

TMD Position

Figure 17: Comparison of the percentage of reduction in the maximum actual response in the 15 -storey structure model with an eccentricity of $10 \%$ in both linear and nonlinear modes

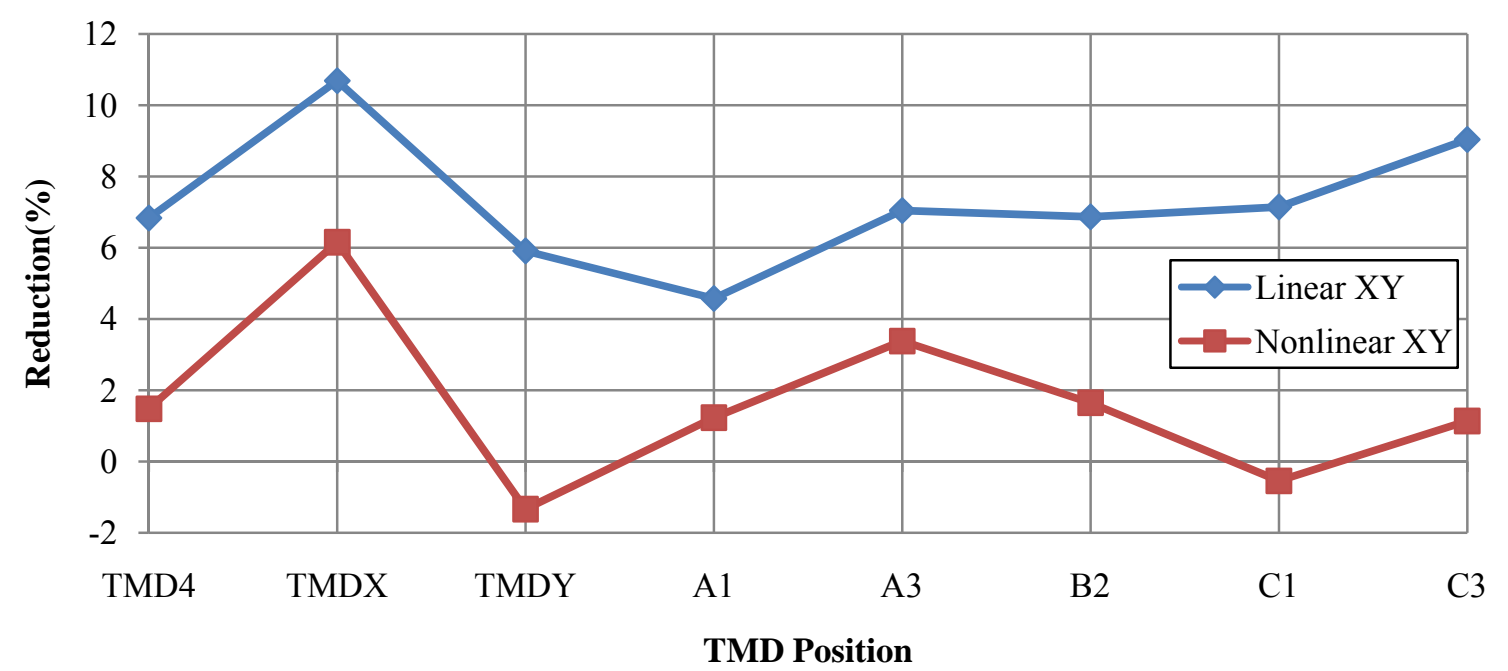

Figure 18: Comparison of the percentage of reduction in the maximum actual response in the 15-storey structure model with an eccentricity of $15 \%$ in both linear and nonlinear modes

By comparing two linear and nonlinear modes, it is observed that in non-linear mode, the damper efficiency is reduced compared to linear mode.

\subsection{Optimization based on the reduction in the maximum base and storey shear \\ 2.2.1 Linear Mode}

The maximum base shears in different TMD positions for the linear model with the eccentricities of $10 \%$ and 15\% are shownIn Figures 19 and 20. In Table 6-23, reduction in base shear, as well as, reduction in storey shear, for that floor on which the greatestrelative floor displacement occurred, i.e. the eleventh floor, for both eccentricities in the linear model, are listed in percentage. 


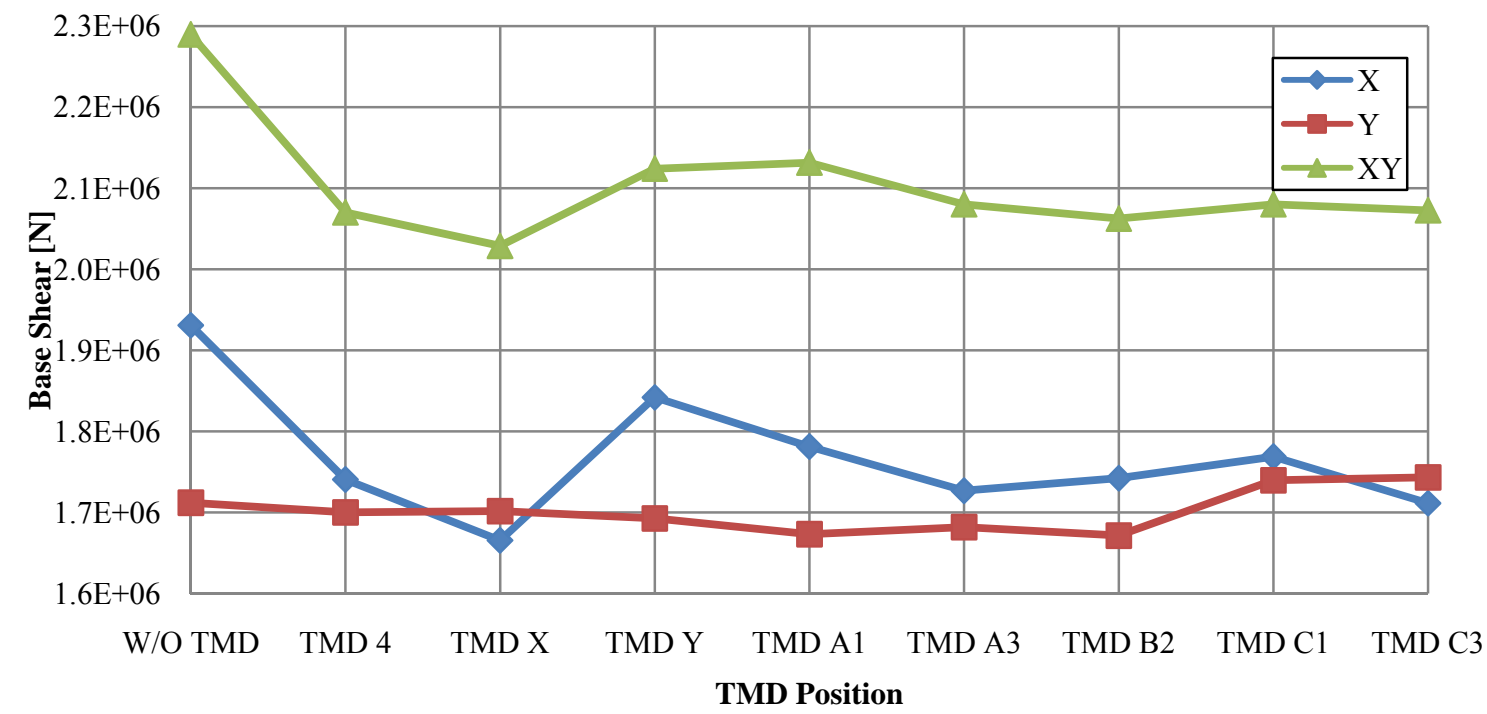

Figure 19. Maximum base shear in different positions of TMDs in the linear 15-storey structure model with an eccentricity of $10 \%$

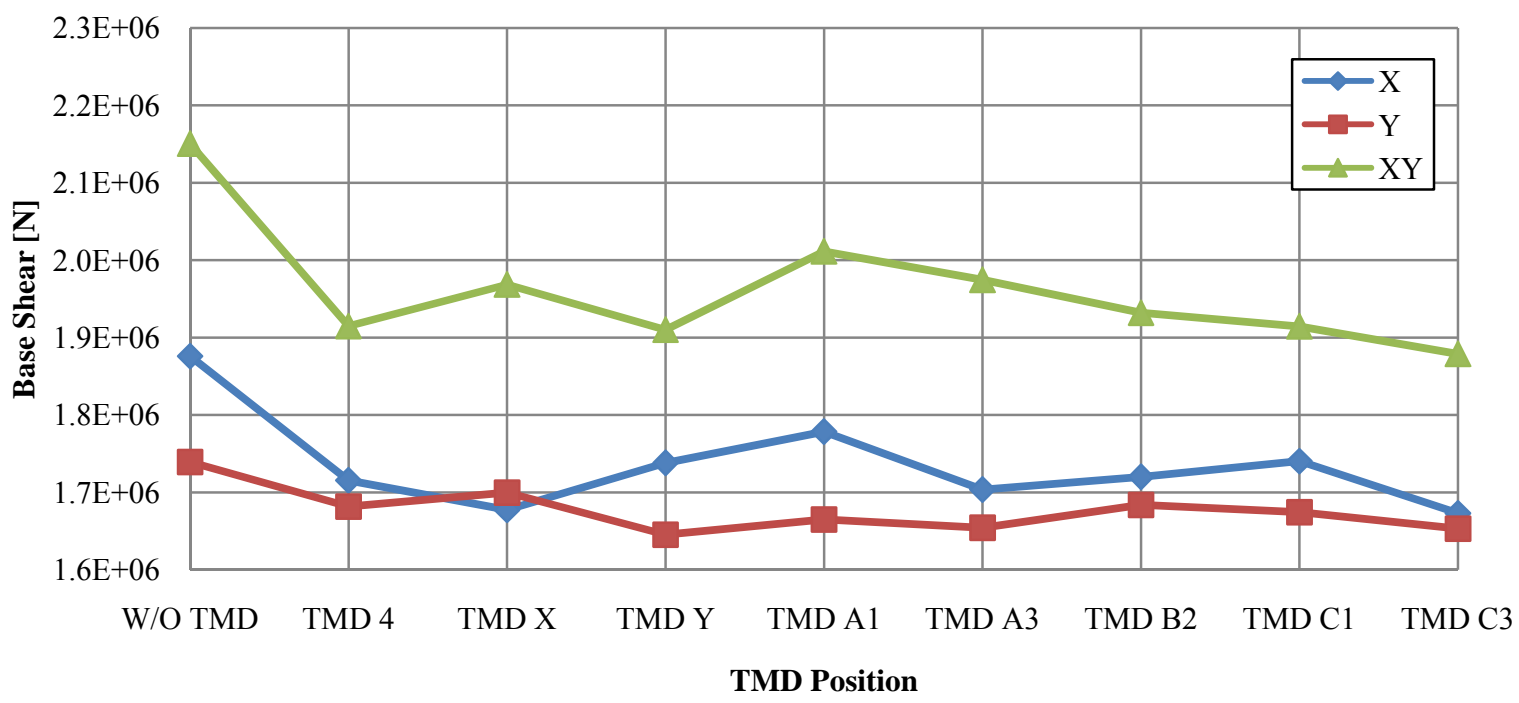

Figure 20. Maximum base shear in different positions of TMDs in the linear 15-storey structure model with an eccentricity of $15 \%$ Table10. Reduction in base shear and the $11^{\text {th }}$ storey shear in the linear 15 -storey structure model with the eccentricities of $10 \%$ and $15 \%$

\begin{tabular}{|c|c|c|c|c|c|c|c|c|c|c|c|c|}
\hline \multirow{3}{*}{$\begin{array}{l}\text { TMD } \\
\text { Pos. }\end{array}$} & \multicolumn{6}{|c|}{ Ecc. $10 \%$} & \multicolumn{6}{|c|}{ Ecc. $15 \%$} \\
\hline & \multicolumn{3}{|c|}{$\begin{array}{c}\text { Base Shear Reduction } \\
(\%)\end{array}$} & \multicolumn{3}{|c|}{$\begin{array}{l}\text { 11th story Reduction } \\
\qquad(\%)\end{array}$} & \multicolumn{3}{|c|}{$\begin{array}{c}\text { Base Shear Reduction } \\
(\%)\end{array}$} & \multicolumn{3}{|c|}{$\begin{array}{l}11 \text { th story Reduction } \\
(\%)\end{array}$} \\
\hline & $X$ & $\mathrm{Y}$ & $X Y$ & X & $\mathrm{Y}$ & $\mathrm{XY}$ & $\mathrm{X}$ & $\mathrm{Y}$ & $X Y$ & $X$ & Y & $\mathrm{XY}$ \\
\hline TMD4 & 9.86 & 0.70 & 9.58 & 5.35 & -2.29 & 4.38 & 8.56 & 3.31 & 10.96 & 4.22 & $\begin{array}{c}- \\
0.19\end{array}$ & 4.40 \\
\hline TMDX & 13.75 & 0.61 & 11.39 & 8.79 & -0.21 & 5.85 & 10.59 & 2.27 & 8.46 & 5.15 & 2.43 & 4.71 \\
\hline TMDY & 4.61 & 1.13 & 7.23 & 1.42 & -2.21 & 3.68 & 7.35 & 5.40 & 11.18 & 2.50 & 1.71 & 3.48 \\
\hline A1 & 7.75 & 2.27 & 6.91 & 3.36 & -0.96 & 2.55 & 5.20 & 4.27 & 6.47 & 1.70 & 2.14 & 2.26 \\
\hline A3 & 10.57 & 1.76 & 9.15 & 5.98 & -1.81 & 3.90 & 9.19 & 4.88 & 8.18 & 5.23 & 0.62 & 3.76 \\
\hline B2 & 9.77 & 2.37 & 9.92 & 4.80 & -0.98 & 4.34 & 8.32 & 3.19 & 10.16 & 3.48 & 1.19 & 3.80 \\
\hline $\mathrm{C} 1$ & 8.39 & -1.61 & 9.15 & 4.15 & -3.50 & 4.39 & 7.23 & 3.73 & 10.98 & 2.80 & 1.12 & 4.09 \\
\hline C3 & 11.37 & -1.82 & 9.47 & 7.24 & -1.77 & 6.35 & 10.82 & 4.95 & 12.63 & 6.24 & 0.05 & 6.65 \\
\hline
\end{tabular}


According to Figures 19 and 20, and also Table 10, it is shown that in most cases, TMDs decreased the base shear in both directions.

\subsubsection{Nonlinear mode}

The maximum base shears in different TMD positions for the non-linear model with the eccentricities of $10 \%$ and 15\% are shownIn Figures 21 and 22. In Table 11, reduction in base shear, as well as, reduction in storey shear, for that floor on which the greatestrelative floor displacement occurred, i.e. the eleventh floor, are listed in percentage.

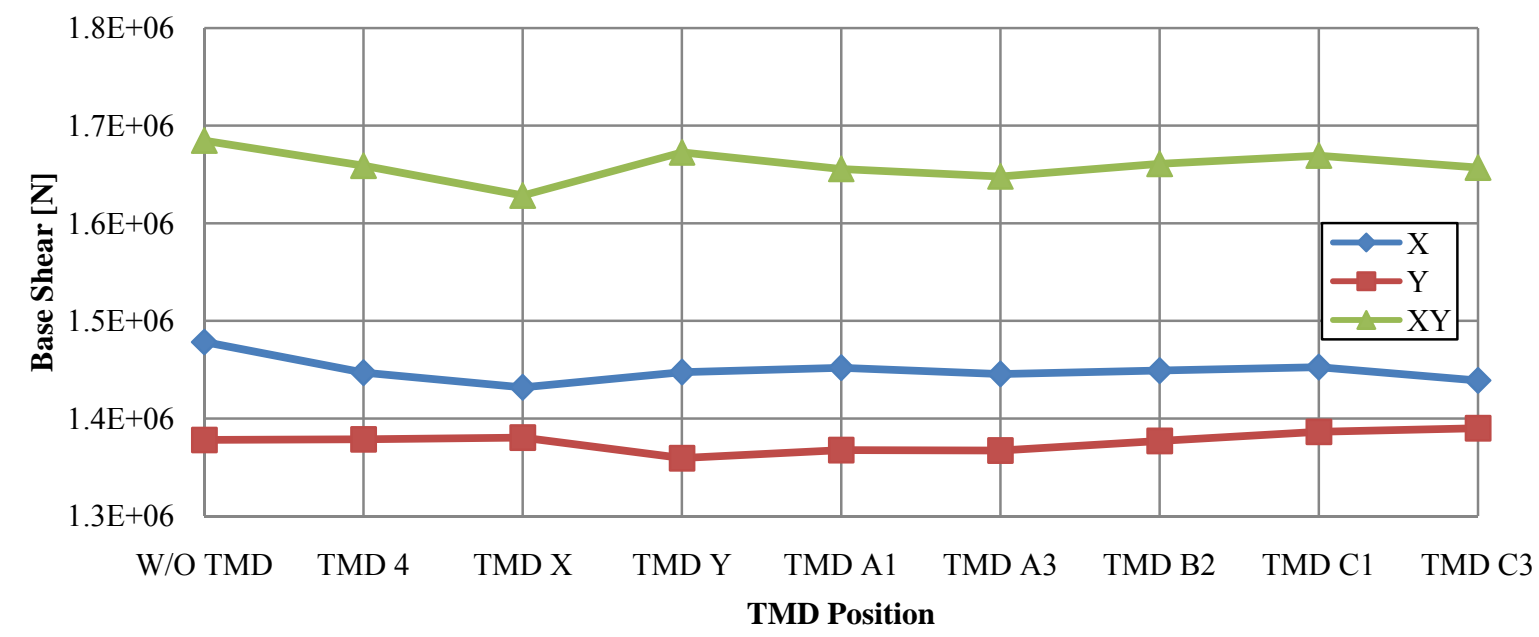

Figure 21. Maximum base shear in different positions of TMDs in the non-linear 15-storey structure model with an eccentricity of $10 \%$

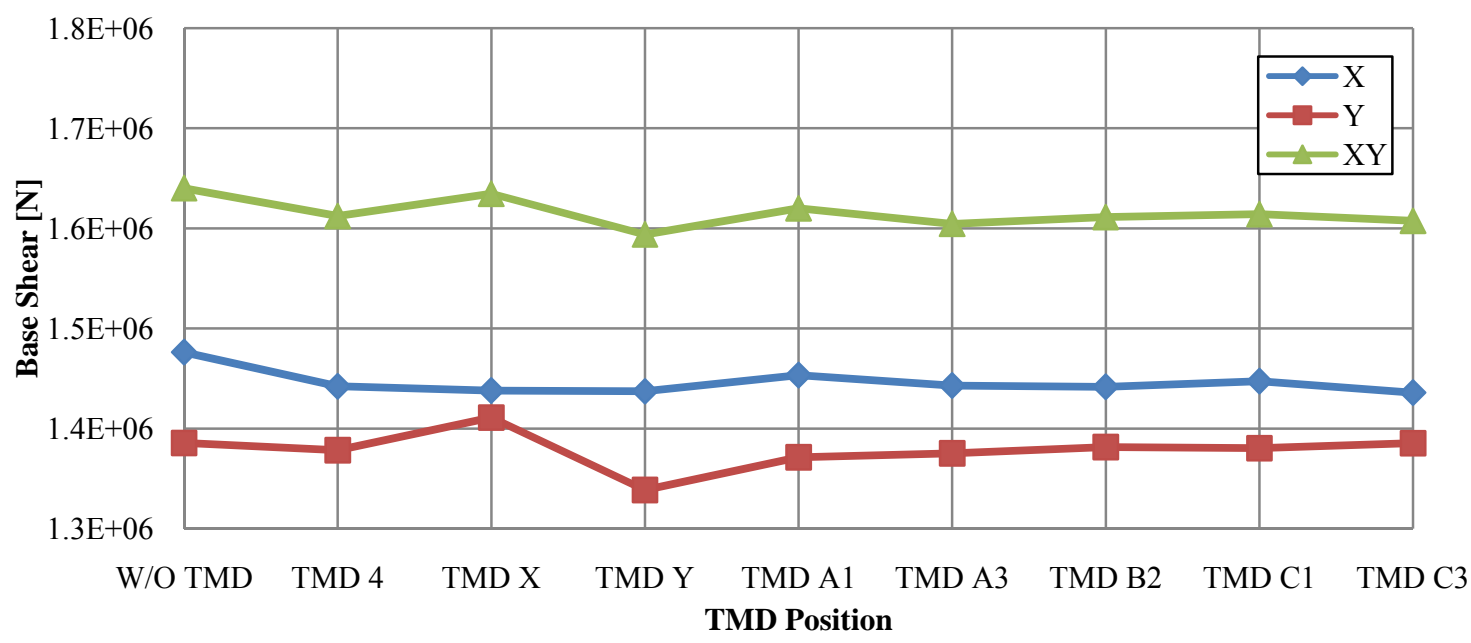

Figure 22. Maximum base shear in different positions of TMDs in the non-linear 15-storey structure model with an eccentricity of $15 \%$

Table10. Reduction in base shear and the $11^{\text {th }}$ storey shear in the non-linear 15 -storey structure model with theeccentricitiesof $10 \%$ and $15 \%$

\begin{tabular}{|c|c|c|c|c|c|c|c|c|c|c|c|c|}
\hline \multirow{3}{*}{$\begin{array}{l}\text { TMD } \\
\text { Pos. }\end{array}$} & \multicolumn{6}{|c|}{ Ecc. $10 \%$} & \multicolumn{6}{|c|}{ Ecc. $15 \%$} \\
\hline & \multicolumn{3}{|c|}{$\begin{array}{c}\text { Base Shear Reduction } \\
(\%)\end{array}$} & \multicolumn{3}{|c|}{$\begin{array}{l}\text { 11th story Reduction } \\
\qquad(\%)\end{array}$} & \multicolumn{3}{|c|}{$\begin{array}{c}\text { Base Shear Reduction } \\
(\%)\end{array}$} & \multicolumn{3}{|c|}{$\begin{array}{l}11 \text { th story Reduction } \\
(\%)\end{array}$} \\
\hline & $X$ & $\mathrm{Y}$ & $\mathrm{XY}$ & $X$ & $\mathrm{Y}$ & $\mathrm{XY}$ & $X$ & $\mathrm{Y}$ & $\mathrm{XY}$ & $X$ & Y & $\mathrm{XY}$ \\
\hline TMD4 & 2.13 & -0.05 & 1.53 & -0.67 & 1.14 & 0.78 & 2.31 & 0.52 & 1.69 & 1.40 & 0.66 & 0.05 \\
\hline TMDX & 3.14 & -0.17 & 3.34 & 0.44 & -0.04 & 1.83 & 2.60 & -1.83 & 0.34 & 1.35 & 2.52 & 0.66 \\
\hline TMDY & 2.09 & 1.35 & 0.72 & -1.64 & 3.72 & -0.26 & 2.64 & 3.39 & 2.82 & 1.15 & -0.55 & 1.02 \\
\hline A1 & 1.78 & 0.75 & 1.72 & -1.23 & 1.09 & 0.70 & 1.55 & 1.03 & 1.23 & 0.43 & 0.39 & 0.05 \\
\hline A3 & 2.22 & 0.78 & 2.18 & -0.69 & 1.54 & 0.98 & 2.26 & 0.75 & 2.17 & 1.41 & 0.82 & 0.46 \\
\hline $\mathrm{B} 2$ & 1.98 & 0.07 & 1.42 & -0.53 & 1.93 & 0.71 & 2.34 & 0.30 & 1.76 & 1.70 & 1.14 & 0.30 \\
\hline $\mathrm{C} 1$ & 1.74 & -0.61 & 0.91 & -0.71 & 0.26 & 0.58 & 1.96 & 0.38 & 1.58 & 1.10 & 1.91 & -0.03 \\
\hline C3 & 2.67 & -0.87 & 1.64 & -0.02 & 2.01 & 0.87 & 2.74 & 0.02 & 1.99 & 2.45 & 1.14 & 0.32 \\
\hline
\end{tabular}


According to Fig. 6- 64 and Fig. 6- 65, as well as Table 6- 24, it is observed that in nonlinear mode, TMDs have also been able to reduce the base shear, although this reduction is less compared to linear mode.

In figures 23 and 24, percentage of reduction in the actual base and the $11^{\text {th }}$ storey shears are shown for both linear and nonlinear modes for the eccentricities of $10 \%$ and $15 \%$. As can be seen, the damper efficiency in nonlinear mode is lower than linear mode. Another note that can be understood from the following figures is that the sensitivity of the change in shearto the position of TMDs in nonlinear mode is less.

Eccentricity of $10 \%$

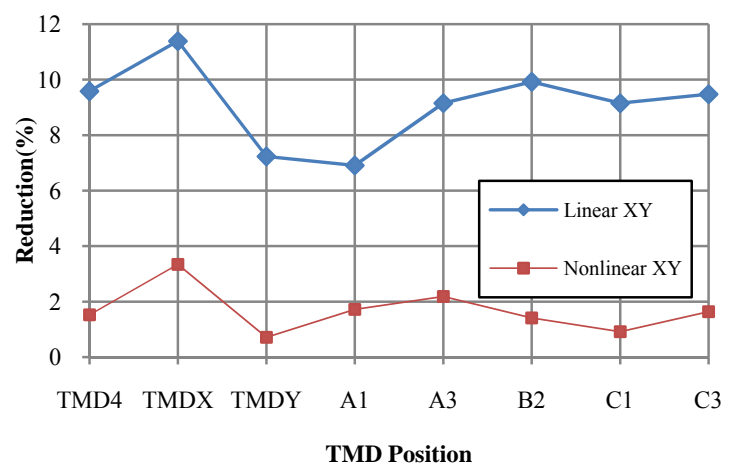

eccentricity of $15 \%$

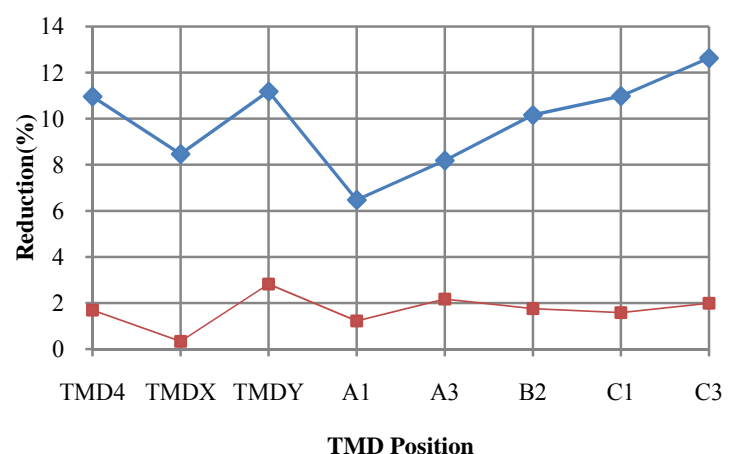

Figure 23. Comparison of the percentage of reduction in the actual base shear in the 15-storey structure model with an eccentricity in the two linear and nonlinear modes

Eccentricity of $10 \%$

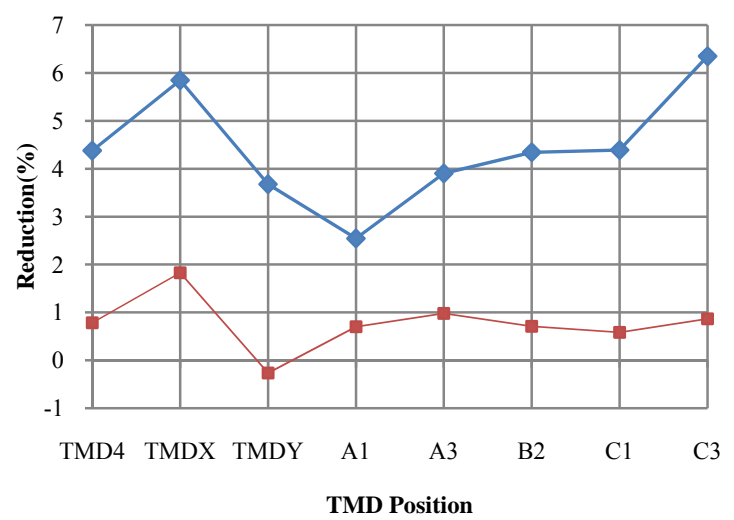

eccentricity of $15 \%$

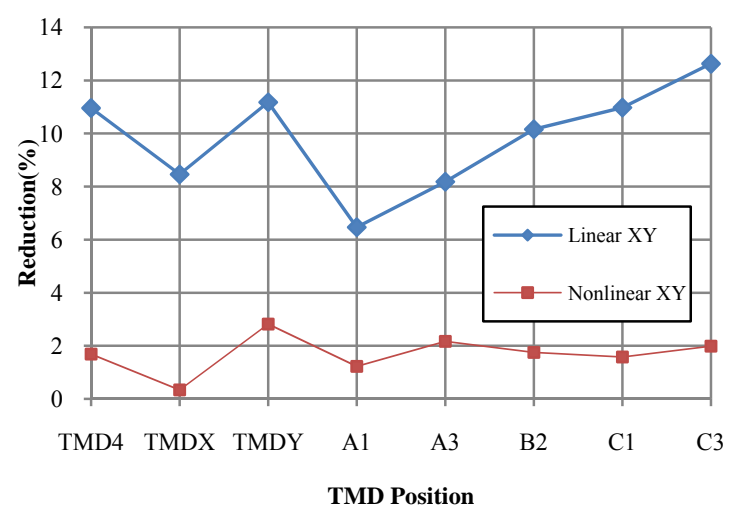

Figure 23. Comparison of the percentage of reduction in the actual 11 th storey shear in the 15 -storey structure model with an eccentricity in the two linear and nonlinear modes

\section{Results of models comparison}

The results are presented in the following table:

Table 12. TMD optimum position in different structures

\begin{tabular}{|c|c|c|c|c|c|c|c|c|}
\hline \multirow{3}{*}{ Story } & \multirow{3}{*}{ Ecc. [\%] } & \multicolumn{7}{|c|}{ TMD Optimum Position } \\
\hline & & \multicolumn{3}{|c|}{ Nonlinear } & \multicolumn{3}{|c|}{ Linear } & \multirow{2}{*}{ overall } \\
\hline & & Base Shear & Story Shear & Drift Ratio & Base Shear & Story Shear & Drift Ratio & \\
\hline \multirow{3}{*}{8} & 0 & B2 & TMDY & TMDY & B2 & B2 & B2 & B2 \\
\hline & 10 & $\mathrm{C} 3$ & TMDY & TMDY & $\mathrm{C} 3$ & $\mathrm{C} 3$ & $\mathrm{C} 3$ & $\mathrm{C} 3$ \\
\hline & 15 & TMD4 & TMDY & TMDY & $\mathrm{C} 3$ & $\mathrm{C} 3$ & $\mathrm{C} 3$ & $\mathrm{C} 3$ \\
\hline \multirow{3}{*}{4} & 0 & TMDY & $\mathrm{C} 3$ & B2 & B2 & A1 & B2 & B2 \\
\hline & 10 & $\mathrm{C} 3$ & $\mathrm{C} 3$ & $\mathrm{C} 3$ & $\mathrm{C} 3$ & $\mathrm{C} 3$ & $\mathrm{C} 3$ & $\mathrm{C} 3$ \\
\hline & 15 & $\mathrm{C} 3$ & $\mathrm{C} 3$ & $\mathrm{C} 3$ & $\mathrm{C} 3$ & $\mathrm{C} 3$ & $\mathrm{C} 3$ & $\mathrm{C} 3$ \\
\hline \multirow{3}{*}{15} & 0 & TMDX & $\mathrm{C} 3$ & TMDX & B2 & B2 & B2 & B2 \\
\hline & 10 & TMDX & TMDX & TMDX & TMDX & $\mathrm{C} 3$ & $\mathrm{C} 3$ & $\mathrm{C} 3$ \\
\hline & 15 & TMDY & TMDY & TMDX & $\mathrm{C} 3$ & $\mathrm{C} 3$ & $\mathrm{C} 3$ & $\mathrm{C} 3$ \\
\hline
\end{tabular}


According to Table 12, it can be concluded that for the mode without eccentricity, the optimum TMD position is $\mathrm{B} 2$, and for the structures eccentricity, the optimum TMD position is $\mathrm{C} 3$. In the following figure, the percentage of reduction in the maximum response in various structures and with different eccentricitiesin two linear and nonlinear modes are presented. According to the figure, it can be said that with increasing height, the damper efficiency decreased in both linear and nonlinear modes. The reason for this is that increase in the effect of higher modes on the entire system vibration due to increasing height results inreduction in decreasing effect of damper. In the eight-story structure, with the increase in eccentricity, the damper efficiency decreased, while in other structures, this is not true. In general, one cannot comment on the effect of eccentricity on the damper efficiency, but by comparing linear and nonlinear modes, it can be said that in nonlinear mode, the effect of eccentricity on the damper efficiency is less compared to linear mode.

\section{Linear behavior nonlinear behavior}
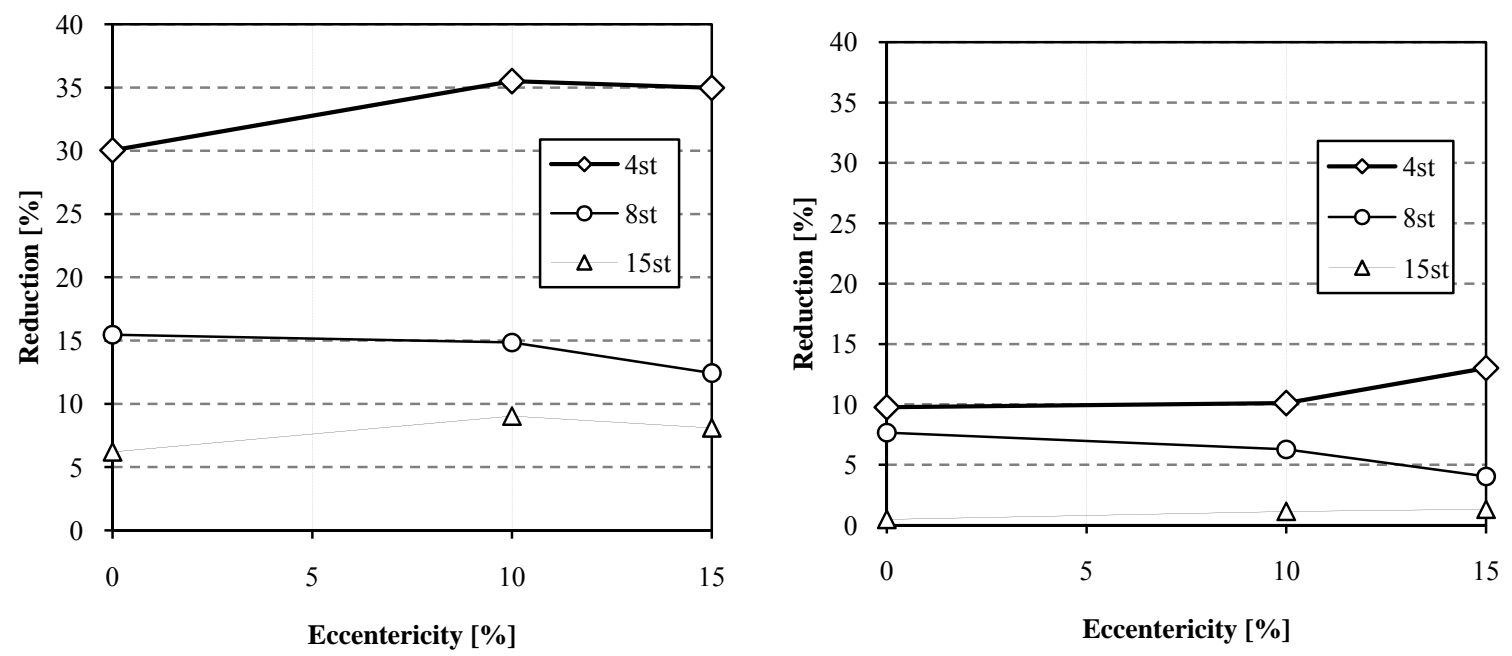

Figure 25. Percentage of reduction in maximum response in various structureswith different eccentricities

\section{Conclusions}

In present study, structure models with different characteristics and modes have been investigated. In order to find the TMD optimum position, nonlinear time history analysis was performed om three models with different number of floors, in three modes of without eccentricity and, with eccentricities of $10 \%$ and $15 \%$ under the eleven earthquake records applied to the structures bi-directionally and simultaneously byconsidering the linear and nonlinear behavior of the eight different TMD positions. Obviously, the conclusions have been made only using limited structure models and a limited group of earthquake records. Since various parameters such as the design of structures, the frequency of earthquake records and so on are involved in modeling, one can expect changes in the results. The results are as follows:

1. In linear structure models without eccentricity, the optimum positions of two dampers is to place both in the center of rigidity. For the models with eccentricity, it can be said that the optimum position is to place the dampers on the soft edge (The edge where the mass is between it and the center of rigidity).

2. In nonlinear structure models, the structure response has a small sensitivity to the damper position, but in general, the damper located in the strong direction of the building performs better because it is less exits from the adjusted mode.

3. Increasing the height, the efficiency of the dampers in both linear and nonlinear modes has decreased. The reason for this is that increase in the effect of higher modes on the entire system vibration due to increasing height results inreduction in decreasing effect of damper.

4. In the eight-story structure, with the increase in eccentricity, the damper efficiency decreased, while in other structures, this is not true. In general, one cannot comment on the effect of eccentricity on the damper efficiency, but by comparing linear and nonlinear modes, it can be said that in nonlinear mode, the effect of eccentricity on the damper efficiency is less compared to linear mode. 


\section{Suggestions}

In order to continue the study, the following suggestions can be offered:

1. It is recommended to usegreater number of records, especially for different soils, and to use different maximum accelerations to evaluate the effect of non-linearization of the structure on the damper efficiency.

2. It is recommended to comprehensively consider the failure criteria to assess the reduced damage to the structure if a tuned mass damper is used.

3. It is recommended to find the optimumTMD parameters to improve its efficiency in controlling nonlinear behavior of structures.

4. It is recommended to use multiple tuned mass dampers in each direction to include a greater frequency range, especially for structures with nonlinear behavior.

\section{Reference}

[1] T.T.Soong, G.F.Dargush. Passive Energy Dissipation Systems in Structural Engineering. New York : John Wiley \& Sons, 1997. 0471-96821-8.

[2] Evaluation of the tuned mass damper efficiency in controlling the seismic behavior of three-dimensional structure models. JavadianArzaghi, Sharareh. 2005. Master's thesis. Faculty of Civil Engineering, Sharif University of Technology.

[3] Farzad Naeim, International Conference of Building Officials, Structural Engineers Association National Council. The seismic design handbook. 2. s.1. : Springer, 2001. 0792373014

[4] [Online] http://en.wikipedia.org/wiki/Base_isolation.

[5] Supplemental energy dissipation: state-of-the-art and state-of-the-practice. Soong, T. T. and Spencer, B. F. 3, s.1. : Elsevier Science Ltd., 2002, Engineering Structures, Vol. 24, pp. 243-259.

[6] A STATE-OF-THE-ART REVIEW ON ACTIVE CONTROL OF STRUCTURES. T.K.Datta. March 2003, ISET Journal of Earthquake Technology, Vol. 40, pp. 1-77.

[7] Control performance of active-passive composite tuned mass damper. Nishimura, Isao, et al. s.1. : IOP Publishing Ltd., 1998, Smart Mater. Struct., Vol. 7, pp. 637-653.

[8] Examination of mass damper systems in high-rise buildings. KhodaparastRasooli, Shahin. 1999. Master's thesis. Faculty of Civil Engineering, Khaje Nasir Al-Din Al-Tusi University of Technology.

[9] Effect of soil -structureinteraction on the tuned mass damper in reducing the Seismic response of three-dimensional Models. Rahmani Shamsi, Ismail. 2007. Master's thesis. Faculty of Civil Engineering, Sharif Universityof Technology.

[10] Active response control of buildings Active response control of buildings response control system with variable structural characteristics. Kobori, Takuji, et al. s.1. : IOP Publishing Ltd., 1998, Smart Mater. Struct., Vol. 7, pp. $522-529$.

[11] Semi-active control systems for seismic protection of structures: a state-of-the-art review. Symans, Michael D. and Constantinou, Michael C. 6, 1999, Engineering Structures, Vol. 21, pp. 469-487.

[12] Constrained reliability-based optimization of linear tuned mass dampers for seismic control. Giuseppe Carlo Marano, Rita Greco, Francesco Trentadue, Bernardino Chiaia,. 44, s.1. : Elsevier, 2007, International Journal of Solids and Structures, pp. 7370-7388. 